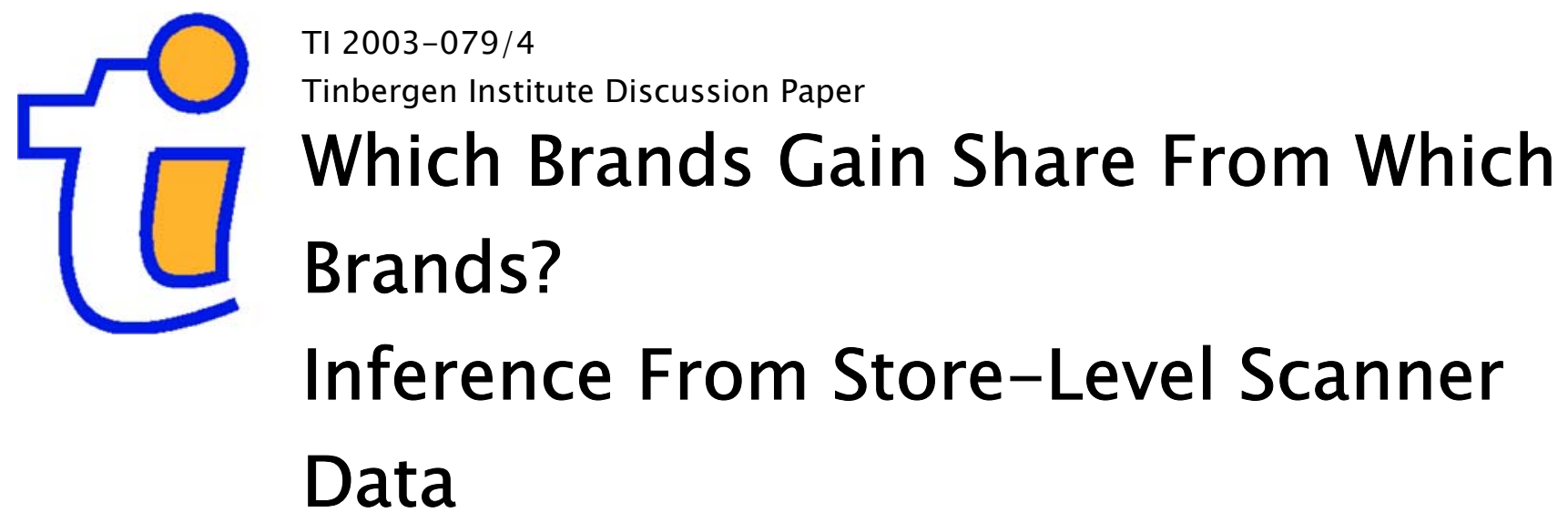

Rutger van Oest

Philip Hans Franses*

Faculty of Economics, Erasmus Universiteit Rotterdam, and Tinbergen Institute.

*Econometric Institute. 


\section{Tinbergen Institute}

The Tinbergen Institute is the institute for economic research of the Erasmus Universiteit Rotterdam, Universiteit van Amsterdam, and Vrije Universiteit Amsterdam.

Tinbergen Institute Amsterdam

Roetersstraat 31

1018 WB Amsterdam

The Netherlands

Tel.: $\quad+31(0) 205513500$

Fax: $\quad+31(0) 205513555$

Tinbergen Institute Rotterdam

Burg. Oudlaan 50

3062 PA Rotterdam

The Netherlands

Tel.: $\quad+31(0) 104088900$

Fax: $\quad+31(0) 104089031$

Please send questions and/or remarks of nonscientific nature to driessen@tinbergen.nl.

Most TI discussion papers can be downloaded at http://www.tinbergen.nl. 


\title{
Which brands gain share from which brands? Inference from store-level scanner data
}

\author{
Rutger van Oest* \\ Tinbergen Institute \\ Erasmus University Rotterdam \\ Philip Hans Franses \\ Econometric Institute \\ Erasmus University Rotterdam
}

\begin{abstract}
Market share models for weekly store-level data are useful to understand competitive structures by delivering own and cross price elasticities. These models can however not be used to examine which brands lose share to which brands during a specific period of time. It is for this purpose that we propose a new model, which does allow for such an examination. We illustrate the model for two product categories in two markets, and we show that our model has validity in terms of both in-sample fit and out-of-sample forecasting. We also demonstrate how our model can be used to decompose own and cross price elasticities to get additional insights into the competitive structure.
\end{abstract}

\section{Keywords}

Competitive structure, elasticity decomposition, market shares, share-switching, store-level scanner data

\footnotetext{
${ }^{*}$ Corresponding author: Tinbergen Institute, H16-32, Erasmus University Rotterdam, P.O. Box 1738, 3000 DR Rotterdam (e-mail vanoest@few.eur.nl, tel. +31-10-4088946, FAX +3110-4089162). We wish to thank Harald van Heerde for his useful comments, and Martijn van der Molen for preparing the data. The results in the paper have been obtained using Ox v3.30 (Doornik 1998).
} 


\section{Introduction and motivation}

This paper deals with the analysis of, say, weekly observed store-level scanner data, with the purpose of linking market shares with marketing instruments like price and promotion. A typical format of such analysis is a regression type model, which, in the case of market shares, is often a market share attraction model, see Cooper and Nakanishi (1988) and Cooper (1993) for detailed early treatments and Fok, Franses and Paap (2002) for a recent review of its econometric properties. Such an attraction model delivers, amongst other things, estimates of own and cross price elasticities, which in turn can be used to draw inference on the competitive structure. With these elasticities, one can infer, for example, what might happen to the own brand market share if the own price is lowered or when competitors lower their prices.

Market share models are useful to sketch competitive structures. However, there is one thing these models cannot do, and that is, to help to understand which brands lose share to which brands. To make this statement more precise, think about the following situation. There are two brands, A and B, and we observe weekly sales of these brands. Suppose for the moment that the same number of households visits the store in each week. If the price of, say, A is lowered in a certain week, we might observe more sales of $\mathrm{A}$ and less of $\mathrm{B}$. This information might be useful to see if lower prices generate more sales, but it is insufficient to understand whether the change in sales of A can be fully attributed to households who change from B to A, or whether some buyers of A have also switched to B. Hence, the question where the new sales come from cannot be addressed by simply looking at weekly sales or at shares data.

Alternatively, one might turn to a micro analysis using household scanner panel data to get insight into brand-switching. These micro data are more detailed than macro store-level data, but for household scanner panel data there are some problems too. One of these is the availability, that is, scanner panel data are relatively scarce, and it is often expensive to acquire them. A second problem is the representativeness of these data, which depends on the size of the panel and on the way participating 
households have been selected. Moreover, even if a household panel is representative, the effective sample which is eventually considered in the analysis might not be representative, as it is often necessary to exclude households. A reason for exclusion might be that households do not make enough purchases during a specific time period, see for example Bucklin and Lattin (1991) and Guadagni and Little (1983). The representativeness issue for household scanner panel data is addressed by Gupta, Chintagunta, Kaul and Wittink (1996). Russell and Kamakura (1994) propose an integrated approach which takes advantage of both the information richness of micro data and the representativeness of macro data. However, their approach does not avoid the availability of scanner panel data.

The aim of this paper is therefore to develop a method to infer share-switching from widely available store-level scanner data. Share-switching is related to aggregated market shares in a similar fashion as brand-switching is related to individual brand choice behavior. Our model can be used to construct share-switching maps, which are useful to get a better understanding of the competitive structure. For example, consider again two brands A and B. It might happen that the cross price elasticities suggest that $\mathrm{A}$ and $\mathrm{B}$ are not strong price competitors, while at the same time much switching does occur between these two brands. In that case, competition between $\mathrm{A}$ and $\mathrm{B}$ might be due to low customer loyalty for both brands. An explanation for such a competition is that households might behave as varietyseekers, that is, households might derive utility from brand-switching itself, besides the utility resulting from the selected brand. McAlister and Pessemier (1982) provide a classification scheme of the variety-seeking literature. In this case, increasing customer loyalty should be more important than pricing strategies.

A second contribution of our model is that it allows for a decomposition of own and cross price elasticities. For example, a decrease of the own price is likely to result in an increase of the own market share. This increased market share is a result of (i) retaining more of the own share (less switching away from the own brand) and (ii) gaining additional share from the other brands (more switching towards the 
own brand). The decomposition from our model makes it possible to quantify these partial effects. This is an additional insight which cannot be obtained from market share attraction models.

The structure of our paper is as follows. In Section 2, we outline in a little more detail the situation, which was already briefly touched upon above, concerning weekly sales of brands and week-to-week share-switching. Next, in Section 3, we put forward our model, and in Section 4, we explain how the model can be used to get insight into the competitive structure. In Section 5, we discuss parameter estimation. In Section 6, we apply our method to four store-level data sets concerning two product categories, each having four brands. Finally, in Section 7, we conclude with a discussion of the implications of our method.

Insert Figure 1 about here.

Insert Figure 2 about here.

\section{On store-level data and share-switching}

Consider the case where we have weekly store-level scanner data, for $t=1, \ldots, T$. For the moment, we assume that $T=2$. Figure 1 sketches a possible situation involving the market shares of three brands A, B and C. At $t=1$ the three brands have shares of $30 \%, 50 \%$ and $20 \%$, while the shares at $t=2$ are given by $36 \%$, $38 \%$ and $26 \%$, respectively. These observed changes in market share from $t=1$ to $t=2$ are the result of unobserved share-switching from and to each of the three brands, which is represented by the arrows. The numbers on the arrows indicate which fraction of the market share at $t=1$ is transferred. So, in the left panel of the figure, brand A retains $80 \%$ of its market share, it loses $10 \%$ of its share to brand B, and it loses another $10 \%$ to brand C. Similarly, brand B retains $70 \%$ of its share, and it loses $20 \%$ and $10 \%$ to brand A and brand C, respectively. It is further seen that brand $\mathrm{C}$ retains $90 \%$ of its share, whereas the remaining $10 \%$ moves to brand A. It is easily checked that these switching fractions indeed give the market 
shares at time $t=2$. For example, at $t=2$ brand A has a share of $36 \%$, which is $0.80 \times 30 \%+0.20 \times 50 \%+0.10 \times 20 \%$.

However, these share-switching fractions do not uniquely determine the market shares at $t=2$, and the right panel gives another set of share-switching fractions resulting in the same shares. The issue is that there are only three observations (three market shares at $t=2$ ), whereas there are six free parameters to be estimated (nine switching arrows of which three are restricted such that outgoing arrows sum to unity). So, more than two periods have to be considered.

Figure 2 illustrates share-switching when $T=4$ weeks are considered. The shareswitching arrows between $t=1$ and $t=2$ are assumed to be the same as the shareswitching arrows between $t=2$ and $t=3$ and those between $t=3$ and $t=4$, so that the number of free parameters is still six. In principle, the number of market share observations is now sufficient to estimate the values of the share-switching arrows. We note that the share-switching fractions can be correlated to marketing actions through time-invariant response parameters. For example, if a brand decreases its price, this might induce additional switching towards this brand. Clearly, if the switching fractions are correlated with time-varying marketing variables, they are not time-invariant anymore.

\section{The model}

In this section we develop our share-switching model. To this end, we define the market share of brand $j$ at time $t$ by $M_{j, t}, j=1, \ldots, J, t=1, \ldots, T$. Furthermore, we define the fraction of the market share $M_{l, t-1}$ of brand $l$ moving to brand $k$ at time $t$ by $\lambda_{l, k, t}$. It is convenient to collect the market shares observed at time $t$ in the vector $M_{t}=\left(M_{1, t}, \ldots, M_{J, t}\right)^{\prime}$ and to collect the share-switching fractions at time $t$ in the matrix

$$
\Lambda_{t}=\left(\begin{array}{ccc}
\lambda_{1,1, t} & \cdots & \lambda_{1, J, t} \\
\vdots & \ddots & \vdots \\
\lambda_{J, 1, t} & \cdots & \lambda_{J, J, t}
\end{array}\right)
$$


For example, in the left panel of Figure 1 we would have

$$
M_{t-1}=\left(\begin{array}{c}
0.30 \\
0.50 \\
0.20
\end{array}\right), \quad M_{t}=\left(\begin{array}{c}
0.36 \\
0.38 \\
0.26
\end{array}\right), \quad \Lambda_{t}=\left(\begin{array}{ccc}
0.80 & 0.10 & 0.10 \\
0.20 & 0.70 & 0.10 \\
0.10 & 0 & 0.90
\end{array}\right)
$$

The share-switching fractions as contained in $\Lambda_{t}$ satisfy two conditions. First, these share-switching fractions just redistribute each brand's market share, so that they have to sum to one for each given brand, that is,

$$
\sum_{k=1}^{J} \lambda_{l, k, t}=1, \quad l=1, \ldots, J,
$$

or in matrix notation,

$$
\Lambda_{t} \iota_{J}=\iota_{J}
$$

where $\iota_{J}$ denotes the $J \times 1$ vector consisting of ones. Second, by definition, the current market share of each brand is the sum of the portions carried over to that brand from each brand's previous market share. This leads to the Markov equation

$$
M_{k, t}=\sum_{l=1}^{J} \lambda_{l, k, t} M_{l, t-1}, \quad k=1, \ldots, J
$$

which is also the key equation in the aggregated Markov model of Leeflang (1974), see also Leeflang et al. (2000). In matrix notation, it is given by

$$
M_{t}=\Lambda_{t}^{\prime} M_{t-1}
$$

In Appendix A we outline the model of Leeflang (1974) and how it fundamentally differs from ours in various respects.

We have already mentioned that the share-switching fractions $\lambda_{l, k, t}$ might be correlated to marketing activity. However, even if such observable variables are included, it cannot not be expected that share-switching is fully explained. In order to account for this, we decompose the share-switching matrix $\Lambda_{t}$ into a deterministic component $\tilde{\Lambda}_{t}$ and a random component $E_{t}$, that is,

$$
\Lambda_{t}=\tilde{\Lambda}_{t}+E_{t}
$$


where

$$
\tilde{\Lambda}_{t}=\left(\begin{array}{ccc}
\tilde{\lambda}_{1,1, t} & \cdots & \tilde{\lambda}_{1, J, t} \\
\vdots & \ddots & \vdots \\
\tilde{\lambda}_{J, 1, t} & \cdots & \tilde{\lambda}_{J, J, t}
\end{array}\right), \quad E_{t}=\left(\begin{array}{ccc}
e_{1,1, t} & \cdots & e_{1, J, t} \\
\vdots & \ddots & \vdots \\
e_{J, 1, t} & \cdots & e_{J, J, t}
\end{array}\right)
$$

All elements of the error matrix $E_{t}$ are assumed to have expectation zero, so that the expectation of the share-switching matrix $\Lambda_{t}$ is $\tilde{\Lambda}_{t}$. Substituting (5) into (4) gives

$$
M_{t}=\tilde{\Lambda}_{t}^{\prime} M_{t-1}+E_{t}^{\prime} M_{t-1}
$$

decomposing market shares into an explained and an unexplained component. This constitutes the first part of our model.

In order to interpret the elements of $\tilde{\Lambda}_{t}$ (which have to be estimated using actual data) as share-switching fractions, we require that the "redistribution condition" is maintained, that is,

$$
\tilde{\Lambda}_{t} \iota_{J}=\iota_{J}
$$

By postmultiplying both sides of (5) by $\iota_{J}$ and substituting (2) and (7), it follows that the rows of the error matrix $E_{t}$ have to sum to zero, that is,

$$
E_{t} \iota_{J}=0
$$

or

$$
\sum_{k=1}^{J} e_{l, k, t}=0, \quad l=1, \ldots, J .
$$

Next, by transposing (6), postmultiplying both sides by $\iota_{J}$, and incorporating the conditions (7) and (8), it follows that

$$
\begin{aligned}
& M_{t}^{\prime} \iota_{J}=M_{t-1}^{\prime} \tilde{\Lambda}_{t} \iota_{J}+M_{t-1}^{\prime} E_{t} \iota_{J} \\
\Leftrightarrow & M_{t}^{\prime} \iota_{J}=M_{t-1}^{\prime} \iota_{J}+M_{t-1}^{\prime} 0 \\
\Leftrightarrow & 1=1+0 .
\end{aligned}
$$

So, both the observed market shares $M_{t}=\Lambda_{t}^{\prime} M_{t-1}$ and the predicted market shares $\tilde{\Lambda}_{t}^{\prime} M_{t-1}$ sum to unity, which is an important feature of a model for market shares. Furthermore, it follows from (10) that one of the $J$ market share equations in (6) is redundant, so that only the parameters of $J-1$ equations have to be estimated. 
In order to complete the model, we specify the elements of $\tilde{\Lambda}_{t}$ and we assume a distribution for the elements of the error matrix $E_{t}$. We define the elements of $\tilde{\Lambda}_{t}$ by

$$
\tilde{\lambda}_{l, k, t}=\frac{\exp \left(\alpha_{l, k}+x_{k, t}^{\prime} \beta\right)}{\sum_{j=1}^{J} \exp \left(\alpha_{l, j}+x_{j, t}^{\prime} \beta\right)}, \quad l=1, \ldots, J, \quad k=1, \ldots, J
$$

so that the redistribution condition (7) is indeed satisfied. Similar to the conditional logit model of McFadden (1974), not all intercept parameters $\alpha_{l, k}$ are identified. For identification purposes, we set $\alpha_{l, J}=0, l=1, \ldots J$. These parameters correspond to the redundant $J$-th market share equation. It is seen from (11) that each shareswitching fraction $\tilde{\lambda}_{l, k, t}$ from brand $l$ to brand $k$ has its own intercept with parameter $\alpha_{l, k}$, and that $\tilde{\lambda}_{l, k, t}$ depends on the marketing-mix variables of the receiving brand $k$ through the shared response parameters $\beta$. We note that it is not affected by the marketing-mix of the supplying brand $l$. This is consistent with the brandswitching models of Givon (1984) and Seetharaman and Chintagunta (1998) which aim to describe variety-seeking behavior and habit persistence in brand choice. The marketing-mix variables in $x_{k, t}$ are in first-differences, as share-switching corresponds to changes in market shares, rather than absolute market share levels. We emphasize that, as in the conditional logit model, the estimation results of our share-switching model are invariant with respect to which brand is taken as the base brand $J$.

For the share-switching errors $e_{l, k, t}$, we would want to consider a distribution which is, on one hand, parsimonious in its parameterization, and which, on the other hand, is flexible enough to reflect uncertainty patterns in share-switching. Hence, we assume that the $e_{l, k, t}$ are distributed independently as $N\left(0, \sigma_{k, t}^{2}\right)$ with $\sigma_{k, t}^{2}=\sigma^{2} M_{k, t-1}^{\gamma}$, where $\sigma^{2}$ and $\gamma$ have to be estimated. So, the share-switching errors obey a normal distribution, and they are allowed to be heteroscedastic in the sense that the variance might depend on the market share of the receiving brand $k$. In fact, we expect that $\gamma>0$, as it entails that if the receiving brand has a small market share, it is probably able to take over only relatively small fractions of the other market shares, and hence uncertainty shall be limited. On the other hand, anything can happen when the receiving brand is a powerful brand with a large 
market share.

In Appendix $\mathrm{B}$ we show that if the elements $e_{l, k, t}$ of $E_{t}$ are independently $N\left(0, \sigma^{2} M_{k, t-1}^{\gamma}\right)$ distributed before imposing the error summation restrictions (9), the restriction in (9) implies that our final model reads as

$$
\tilde{M}_{t}=\left(\begin{array}{c}
M_{1, t} \\
\vdots \\
M_{J-1, t}
\end{array}\right) \sim N\left(\mu_{t}, \sigma^{2} V_{t}\right)
$$

where

$$
\mu_{t}=\left(\begin{array}{c}
\sum_{l=1}^{J} \tilde{\lambda}_{l, 1, t} M_{l, t-1} \\
\vdots \\
\sum_{l=1}^{J} \tilde{\lambda}_{l, J-1, t} M_{l, t-1}
\end{array}\right)
$$

and

$$
\begin{aligned}
& V_{t}=\sum_{l=1}^{J} M_{l, t-1}^{2} \\
& {\left[-\frac{1}{\sum_{j=1}^{J} M_{j, t-1}^{\gamma}}\left(\begin{array}{c}
M_{1, t-1}^{\gamma} \\
\vdots \\
M_{J-1, t-1}^{\gamma}
\end{array}\right)\left(M_{1, t-1}^{\gamma} \cdots M_{J-1, t-1}^{\gamma}\right)+\operatorname{diag}\left(M_{1, t-1}^{\gamma}, \ldots, M_{J-1, t-1}^{\gamma}\right)\right] .}
\end{aligned}
$$

It is seen from (14) that the restriction in (9) induces that the market shares are negatively correlated. This is a desirable feature, as, by definition, a larger market share for one brand results in a smaller total market share for all other brands.

\section{Interpretation}

In this section we discuss how our share-switching model can be used to get insight into the competitive structure. The well-known market share attraction model is often used to compute own and cross price elasticities which indicate how the own brand market share reacts to a small price decrease of the own brand or a competitive brand. Our model can be used to obtain such elasticities as well. In order to derive the elasticities, we first introduce some additional notation. We recall 
that $\tilde{\lambda}_{l, k, t}$ is interpreted as the fraction of the share of brand $l$ moving to brand $k$ at time $t$. So, $\tilde{\lambda}_{l, k, t}$ corresponds to share-switching conditional on the supplying brand $l$, that is, the share-switching fractions away from $l$ sum to unity, or $\sum_{k=1}^{J} \tilde{\lambda}_{l, k, t}=1$. As an additional measure, we define the share-switching portion $\bar{\lambda}_{l, k, t}=M_{l, t-1} \tilde{\lambda}_{l, k, t}$, which relates switching from brand $l$ to brand $k$ to the total market. Clearly, $\sum_{l=1}^{J} \sum_{k=1}^{J} \bar{\lambda}_{l, k, t}=1$. The share-switching portion $\bar{\lambda}_{l, k, t}$ is an unconditional measure, which is in contrast with the share-switching fraction $\tilde{\lambda}_{l, k, t}$.

We define the share-switching price elasticity $\delta_{l \rightarrow k, j, t}$ as

$$
\delta_{l \rightarrow k, j, t}=\frac{\partial \bar{\lambda}_{l, k, t}}{\partial p_{j, t}} \frac{p_{j, t}}{\bar{\lambda}_{l, k, t}}=\frac{\partial \tilde{\lambda}_{l, k, t}}{\partial p_{j, t}} \frac{p_{j, t}}{\tilde{\lambda}_{l, k, t}},
$$

where $p_{j, t}$ denotes the price of brand $j$ at time $t$. The interpretation of (15) is that a one percent price increase of brand $j$ at time $t$ results in $\delta_{l \rightarrow k, j, t}$ percent additional share-switching from brand $l$ to brand $k$. We note that $\delta_{l \rightarrow k, j, t}$ is not necessarily zero if $j \neq l, k$, that is, when the price adjustment concerns a brand different from the two brands $l$ and $k$ for which share-switching is considered. For example, if brand $j$ lowers its price, it might gain some share from brand $l$ which would have gone to brand $k$ otherwise. The brand-switching mechanisms, underlying the aggregate response of share-switching to price adjustments, are discussed below.

Basically, if $k \neq l$, brand $j$ might take over some variety-seeking customers of brand $l$ which would otherwise have chosen to switch to brand $k$, as brand $j$ becomes more attractive relative to brand $k$ with its price being unaltered. This idea is in accordance with the brand-switching model of Seetharaman and Chintagunta (1998) which assumes that variety-seekers select the brand which maximizes their utility after excluding the previously purchased brand from consideration. Furthermore, households switching to brand $j$ might also be pure utility maximizers, which is the second group identified in the model of Seetharaman and Chintagunta (1998). In the alternative case that $k=l, \delta_{l \rightarrow k, j, t}$ measures the effectiveness of a price reduction of brand $j$ to take over customers which would otherwise have stayed with brand $l$. Such switching customers are neither involved in variety-seeking (they are willing to buy brand $l$ again) nor habit persistence (they are willing to switch). Note that 
other households might also feature habit persistence, that is, they might stick to brand $l$ and this choice is not affected by the price reduction of brand $j$. These households form the third and most important group in the model of Seetharaman and Chintagunta (1998). The presence of this group decreases the aggregate effect of a competitive price reduction.

If price is one of the marketing-mix variables included in (11), with response parameter $\beta_{p}$, then it can be shown that

$$
\delta_{l \rightarrow k, j, t}=\left\{\begin{array}{ll}
\beta_{p} p_{k, t}\left(1-\tilde{\lambda}_{l, k, t}\right) & \text { if } k=j \\
-\beta_{p} p_{j, t} \tilde{\lambda}_{l, j, t} & \text { if } k \neq j
\end{array} .\right.
$$

These share-switching price elasticities resemble the price elasticities for the conditional logit model. We note that, although prices are considered in first-differences in (11), $p_{j, t}$ in (15) and (16) is defined as the absolute price.

The share-switching price elasticities, derived above, determine the reaction of market shares to price changes, as market shares are eventually the result of shareswitching. For our model, it can be shown that the elasticity of the expected market share $E\left(M_{k, t}\right)=\sum_{l=1}^{J} \bar{\lambda}_{l, k, t}$ with respect to the price $p_{j, t}$ is given by

$$
\delta_{k, j, t}=\frac{\partial E\left(M_{k, t}\right)}{\partial p_{j, t}} \frac{p_{j, t}}{E\left(M_{k, t}\right)}=\frac{\sum_{l=1}^{J} \bar{\lambda}_{l, k, t} \delta_{l \rightarrow k, j, t}}{\sum_{i=1}^{J} \bar{\lambda}_{i, k, t}}
$$

This market-share price elasticity can also be written as

$$
\delta_{k, j, t}=\sum_{l=1}^{J} \eta_{l \rightarrow k, j, t} \quad \text { with } \quad \eta_{l \rightarrow k, j, t}=\frac{\bar{\lambda}_{l, k, t}}{\sum_{i=1}^{J} \bar{\lambda}_{i, k, t}} \delta_{l \rightarrow k, j, t},
$$

where $\eta_{l \rightarrow k, j, t}$ is the contribution of share-switching from brand $l$ to brand $k$ in the overall effect of a price adjustment of brand $j$ on the market share of brand $k$. So, (18) provides a decomposition of the reaction of market share into components attributable to changes in share-switching from each of the brands towards the brand whose market share is affected. This decomposition provides interesting insights, which cannot be obtained from market share attraction models. For example, a decrease of the own price can be expected to result in an increased market share by (i) retaining a larger part of the own current share (own customers have 
a smaller incentive to switch away) and (ii) taking over additional share from competing brands (customers of competing brands have a larger incentive to switch). The part of the increased market share attributable to retaining more of the own share is $\eta_{k \rightarrow k, j, t} / \delta_{k, j, t}$ with $j=k$, whereas the part attributable to gaining more of the competitive share is given by $1-\left(\eta_{k \rightarrow k, j, t} / \delta_{k, j, t}\right)$. In other words, the decomposition can give insight into which part of the reaction of the own market share to an own price reduction is caused by increased customer retention, and which part is not. We note that each component $\eta_{l \rightarrow k, j, t}$ in the decomposition (18) consists of the share-switching price elasticity $\delta_{l \rightarrow k, j, t}$ multiplied by a weight proportional to the corresponding share-switching portion $\bar{\lambda}_{l, k, t}$. So, contributions are determined by both the price-sensitivity and the relative magnitude of corresponding share-switching.

The price elasticities defined by (17) amount to a generalization of a result established by Bucklin, Russell and Srinivasan (1998). This result is a relationship between price elasticities and aggregate brand-switching, which has been derived on the basis of the conditional logit model. Basically, it states that ${ }^{1}$

$$
\delta_{k, j, t}= \begin{cases}\beta_{p} p_{k, t}\left(1-\tilde{\lambda}_{k, k, t}\right) & \text { if } k=j \\ -\beta_{p} p_{j, t} \tilde{\lambda}_{k, j, t} & \text { if } k \neq j\end{cases}
$$

which, using (16), boils down to

$$
\delta_{k, j, t}=\delta_{k \rightarrow k, j, t}
$$

So, in terms of our model, this relationship states that the reaction of market share on a price adjustment is only caused by the effect on customer retention, and not by the effect on share-switching from competing brands. This is more restrictive than our price elasticity specification.

Our model gives insights into the effects of price adjustments on share-switching and market shares. Furthermore, the model can also be used to infer the magnitude of share-switching across brands. In order to fully understand the price elasticity and share-switching patterns, it is useful to visualize them in two-dimensional maps.

\footnotetext{
${ }^{1}$ Bucklin, Russell and Srinivasan (1998) actually consider the logarithm of price in the conditional logit model, so that the price term disappears in their result.
} 
A competitive map for price elasticities can be constructed as described in Cooper (1988, 1993). Complementary, a share-switching map can be constructed using the multidimensional unfolding technique of Constantine and Gower (1978) or using the multidimensional scaling methodology of DeSarbo and Manrai (1992). In the empirical section we discuss these visualization methods in greater detail.

\section{Parameter estimation}

The parameters of our share-switching model can be estimated using maximum likelihood [ML]. The parameter estimates result from maximization of the log-likelihood function, which is given by

$$
\begin{aligned}
\ln L= & -\frac{(T-1)(J-1)}{2}\left[\ln (2 \pi)+\ln \left(\sigma^{2}\right)\right]+\frac{1}{2} \sum_{t=2}^{T} \log \operatorname{det}\left(V_{t}^{-1}\right) \\
& -\frac{1}{2 \sigma^{2}} \sum_{t=2}^{T}\left(\tilde{M}_{t}-\mu_{t}\right)^{\prime} V_{t}^{-1}\left(\tilde{M}_{t}-\mu_{t}\right)
\end{aligned}
$$

where $\mu_{t}$ and $V_{t}$ are defined by (13) and (14), respectively. We note that the inverse

of $V_{t}$ is given by $V_{t}^{-1}=\frac{1}{\sum_{l=1}^{J} M_{l, t-1}^{2}}\left[M_{J, t-1}^{-\gamma} \iota_{J-1} \iota_{J-1}^{\prime}+\operatorname{diag}\left(M_{1, t-1}^{-\gamma}, \ldots, M_{J-1, t-1}^{-\gamma}\right)\right]$, see also the Appendix. Standard errors are obtained by taking the square roots of the diagonal elements of the estimated covariance matrix, which, in turn, can be computed as minus the inverse of the Hessian of (21) evaluated for the optimal parameter values. Numerical techniques, such as the BFGS algorithm or the Newton-Raphson algorithm, have to be used to get the ML parameter estimates.

Insert Table 1 about here.

\section{Empirical analysis}

In this section we apply our model to weekly store-level scanner data, drawn from the ERIM data base (GSB, University of Chicago) for catsup and peanut butter in the Sioux Falls SD market (henceforth referred to as market 1) and the Springfield MO market (henceforth referred to as market 2). The considered period consists of 124 weeks from 1985 to 1988. The last 20 weeks are used for out-of-sample forecasting. 
For each product category, the number of brands is restricted to four by considering the three largest brands and a "rest brand". This Rest brand represents several smaller brands as well as private labels. We allow for marketing-mix effects by including price and 0/1 display variables. Table 1 contains a few summary statistics. We note that the prices of the Rest brands have been computed by taking the ratio of the aggregated sales in dollars and the aggregated sales in units. The market shares correspond to the number of units sold. It is seen that in general the price of the Rest brand is lower than the prices of the other three brands. Furthermore, the table shows that for both catsup and peanut butter the Rest brand has more displays and a larger market share in the Springfield area than in the Sioux Falls area.

Insert Table 2 about here.

\subsection{Parameter estimates}

Table 2 reports the estimates of the response parameters $\beta_{1}$ and $\beta_{2}$ for price and display and the two variance parameters $\sigma^{2}$ and $\gamma$. These parameters are invariant with respect to the base brand $J$. For the sake of brevity, we do not report the twelve intercept parameters $\alpha_{l, k}, l=1, \ldots, 4, k=1, \ldots, 3$. These intercept parameters are sensitive to which brand is taken as the base brand (compare with the conditional logit model), and they are not of particular interest.

The effect of price on market share is significant at a $1 \%$ level and has the expected sign for both catsup and peanut butter in the two markets. Display has a significant effect (at a 5\% level) with the expected sign for the two catsup markets, but the effect is not significant for the two peanut butter markets. Furthermore, it is seen that the heteroscedasticity parameter $\gamma$ is positive and significant for all four category-market combinations. So, as hypothesized, uncertainty about shareswitching is related to the size of the market share of the receiving brand. 


\subsection{Model fit and predictive performance}

In order to investigate how well our model performs in terms of in-sample fit and out-of-sample forecasting, we compare it with two attraction models. The first competing model is the full effects attraction model in which the attraction of brand $k$ at time $t$ is defined by

$$
A_{k, t}=\exp \left(\alpha_{k}+\sum_{s=1}^{S} \sum_{j=1}^{J} \beta_{(s) j, k} \ln \left(x_{(s) j, t}\right)+\varepsilon_{k, t}\right) .
$$

Here $\alpha_{k}$ is a brand-specific intercept, $x_{(s) j, t}$ is the value of marketing-mix variable $s$ for brand $j$ at time $t$ (in our case, $s=1$ corresponds to price and $s=2$ corresponds to display), $\beta_{(s) j, k}$ is the involved response parameter, and $\varepsilon_{k, t}$ is a disturbance term. The $\varepsilon_{k, t}$ are distributed independently as $N\left(0, \sigma_{k, t}^{2}\right)$. We note that, in this full effects specification, the attraction of a brand may be affected by the marketing-mix variables of each of the considered brands.

Bell, Keeney and Little (1975) show that under certain axioms the market share of a brand is proportional to its attraction, so that

$$
M_{k, t}=\frac{A_{k, t}}{\sum_{i=1}^{J} A_{i, t}}
$$

The full effects attraction model is given by (22) and (23). We note that in case the variables $x_{(s) j, t}$ are considered in levels instead of logarithms, the model above is often referred to as an MNL model for market shares.

The second model we consider is the differential effects specification in which competition is restricted in the sense that the attraction of a brand is only affected by its own marketing-mix, that is, $\beta_{(s) j, k}=0$ if $j \neq k$. The differential effects attraction model is defined by (23) and

$$
A_{k, t}=\exp \left(\alpha_{k}+\sum_{s=1}^{S} \beta_{(s) k} \ln \left(x_{(s) k, t}\right)+\varepsilon_{k, t}\right) .
$$

As our share-switching model is dynamic by definition, we include lagged market shares in (22) and (24) in the same way as price and display are included. The literature often considers one common lagged market share parameter for all brands, see for example Brodie and De Kluyver (1984), Chen, Kanetkar and Weiss (1994), 
Kumar and Heath (1990) and Naert and Weverbergh (1981). However, we find that this does not improve the predictions.

Finally, for comparability with our share-switching model, we consider the MNL specifications of the attraction models described above, that is, lagged market share is in logarithms but price and display are in levels. The impact on in-sample fit and out-of-sample forecasting turns out to be negligible, and conclusions are unaffected.

\section{Insert Table 3 about here.}

We estimate the parameters of the two attraction models by considering a base brand, as outlined in Fok, Franses and Paap (2002). Next, we generate appropriate market share predictions using the simulation approach, described in Fok, Franses and Paap (2002). Table 3 shows the in-sample fit and out-of-sample forecasting performance of the three considered models. It reports the in-sample and out-ofsample values for the Root Mean Squared Prediction Error [RMSE] and the Mean Absolute Prediction Error [MAE].

It is seen from Table 3 that our model has either the best or the second best in-sample fit. For the Sioux Falls catsup market, the fit of our share-switching model (containing 16 parameters) is comparable to the fit of the differential effects model (also containing 16 parameters), but it is worse than the fit of the more flexible full effects model (containing 43 parameters). Furthermore, the fit of our model is in between those of the two other models for the Springfield catsup and the Sioux Falls peanut butter markets. Our model fits the data better than the two attractions models for the Springfield peanut butter market.

Perhaps more interesting than the in-sample fit is the out-of-sample forecasting performance of the three models. It is seen that our share-switching model gives better predictions for three of the four category-market combinations. Our model is only outperformed by the differential effects model for the Sioux Falls catsup market.

In sum, for the considered data our model has a reasonable fit and a good forecasting performance. This demonstrates that our model has predictive validity. Now 
we have established that our model is equally good, or even better than alternative models, we can focus on the fact that our model allows for much more managerially relevant inference.

Insert Table 4 about here.

Insert Table 5 about here.

\subsection{Price elasticity analysis}

Table 4 and Table 5 contain the estimated market-share price elasticities $\delta_{k, j, t}$ for the catsup and peanut butter markets. These elasticities are decomposed into components $\eta_{l \rightarrow k, j, t}$ attributable to changes in share-switching from each of the brands $l$ towards the brand $k$ whose market share is affected when brand $j$ changes its price. For example, Table 4 indicates that in the Sioux Falls catsup market a one percent decrease of the price of Heinz can be expected to result in a $2.27 \%$ increase of the own market share because of increased customer retention. Furthermore, additional switching from Hunts, Del Monte and Rest towards Heinz increases the market share of Heinz by another $1.10 \%, 0.77 \%$ and $0.30 \%$, respectively. The total gain in market share is $4.44 \%$. About $50 \%(\approx 2.27 / 4.44 \times 100 \%)$ is caused by customer retention. The remaining $50 \%$ is attributable to switching from the three competing brands towards Heinz.

The above example illustrates that the elasticity decompositions, reported in Table 4 and Table 5, can give interesting insights into which part of the reaction of the own market share to an own price reduction is caused by increased customer retention and which part is not. Such insights cannot be obtained from market share attraction models. For the catsup and peanut butter brands in the Sioux Falls and Springfield markets, we find that increased customer retention accounts for $28 \%$ to $51 \%$ of the total increase of the own market share when the own price is lowered. On average, this is about $42 \%$. So, we find that the majority of the gain in market share is caused by gaining additional share from competing brands, and not so much by increasing own customer retention. 
As a second example, we mention that Heinz is expected to lose $2.03 \%$ of its market share in the Sioux Falls market if Hunts decreases its price by one percent. Here $1.06 \%$ of the loss is attributable to switching from Heinz to Hunts, that is, decreased customer retention of Heinz, and 0.70 is attributable to additional share retained by Hunts which would have gone to Heinz in case there would not have been a price reduction. Furthermore, $0.22 \%$ is attributable to share of Del Monte going to Hunts, which would have gone to Heinz otherwise. Finally, $0.05 \%$ is attributable to switching from Rest to Hunts. So, about $50 \%(\approx 1.06 / 2.03 \times 100 \%)$ of the total effect of a price reduction of Hunts on the market share of Heinz is caused by decreased customer retention for Heinz. The remaining $50 \%$ is attributable to share-switching in which Heinz is not directly involved.

For the catsup and peanut butter brands in the Sioux Falls and Springfield markets, we find that the part of the decrease in own market share when a competitive brand lowers its price, attributable to decreased own customer retention, is mostly between $20 \%$ and $60 \%$ (44 out of 48 cases). On average, this is about $40 \%$. We find that in most cases (39 out of 48 cases) the majority of the loss in own market share is caused by share-switching in which the own brand is not directly involved. There exists substantial variation, though, in particular in the two catsup markets.

\subsubsection{Asymmetric price competition}

Table 1 shows that for all four category-market combinations the prices of the three national brands are comparable, whereas the price of the Rest brand is substantially

lower. It therefore seems reasonable to assume that the perceived quality of brands summarized in the Rest group is also lower than the perceived quality of the national brands, as otherwise Rest should have an enormous market share. A finding, which is due to Blattberg and Wisniewski (1989), predicts that price promotions are more effective for higher-price higher-quality [HPHQ] brands than for lower-price lowerquality [LPLQ] brands. This means that HPHQ brands can gain more share from LPLQ brands by offering a price reduction than vice versa. Kamakura and Russell (1989) and Allenby and Rossi (1991) provide additional empirical support for this 
asymmetric price competition result. Sethuraman, Srinivasan and Kim (1999) make it an empirical generalization that asymmetric price competition holds in terms of cross-price elasticities.

The literature offers several explanations for this phenomenon. Blattberg and Wisniewski (1989) argue that asymmetric price competition can result from a Ushaped heterogeneity distribution for the quality preferences concerning any two brands with regular prices such that the indifference point is located towards the lower quality end of this distribution. This implies that customers of LPLQ brands are more price sensitive than customers of HPHQ brands. Allenby and Rossi (1991) propose an alternative explanation that price reductions induce positive income effects which stimulate switching from low-quality brands to high-quality brands. They formalize this through rotating utility indifference curves. Hardie, Johnson and Fader (1993) consider reference effects and loss aversion concerning the prices and qualities of brands. They explain asymmetric price competition from the notion that losses in terms of price or quality, incurred by brand-switching, are weighted more heavily than resulting gains. Bronnenberg and Wathieu (1996) conditionally support the result of Blattberg and Wisniewski (1989). They state that it holds if and only if the quality gap between an HPHQ brand and an LPLQ brand is sufficiently large compared to the price gap. If this condition does not hold, asymmetric price competition is reversed.

The market-share price elasticities in Table 4 and Table 5 indicate that asymmetric price competition holds for both catsup and peanut butter in the Sioux Falls market. For example, in the Sioux Falls peanut butter market, Rest loses $2.12 \%$ of its share when Skippy lowers its price by one percent, whereas this is only $1.18 \%$ in the oppositive case. However, it is also seen from the tables that the asymmetric price competition effect is sometimes reversed in the Springfield market. For catsup, a one percent price reduction of Del Monte turns out to be less effective than a one percent price reduction of the Rest brand. For peanut butter, the asymmetric price competition effect of Blattberg and Wisniewski (1989) is reversed for Skippy and Jif 
relative to the cheaper Rest brand. The explanation of Bronnenberg and Wathieu (1996) would be that, in the Springfield market, the perceived difference in quality between these national brands and the Rest brand is insufficient to account for the price difference. We note from Table 1 that the price gap between the national brands and the Rest brand is larger in the Springfield market than in the Sioux Falls market, and that in the Springfield market the Rest brands also have larger market shares. This indicates that the Rest brands offer "good value" in the Springfield market, which is consistent with the Bronnenberg-Wathieu finding.

\subsubsection{Price elasticity maps}

In order to better understand the underlying patterns of the asymmetric marketshare price elasticities $\delta_{k, j, t}$ in Table 4 and Table 5 , these elasticities can be displayed in two-dimensional competitive maps, see Cooper $(1988,1993)$. The main computational step to deduce such a map from the $J \times J$ elasticity matrix $\Delta=\left(\delta_{k, j, t}\right)$ consists of finding a matrix of rank 2 such that it approximates $\Delta$ as good as possible. This rank-2 approximation can be written as $V C^{\prime}$, where both $V$ and $C$ are $J \times 2$ matrices. The matrices $V$ and $C$ can be obtained using the singular value decomposition, see Golub and Van Loan (1989) and Magnus and Neudecker (1999) for textbook discussions on this decomposition. ${ }^{2}$

As the elasticity matrix $\Delta$ is approximated by $V C^{\prime}$, the effect of the price of brand $j$ on the market share of brand $k$, that is $\delta_{k, j, t}$, is approximated by the inner product of the $k$-th row of $V$ and the $j$-th row of $C$. If these two rows are displayed as two vectors from the origin, the inner product (representing the elasticity $\delta_{k, j, t}$ ) is determined by both the vector lengths and the angle between the two vectors. The sharpness of the angle can be interpreted as indicating the influence of a price reduction of brand $j$ on the market share of brand $k$ compared to the influence of this

\footnotetext{
${ }^{2}$ The elements of $V$ and $C$ can be computed using the singular value decomposition of $\Delta$, that is, $\Delta=S W U^{\prime}$, where $W$ is a diagonal matrix containing the singular values of $\Delta$ (the square roots of the eigenvalues of $\Delta \Delta^{\prime}$, or equivalently, the square roots of the eigenvalues of $\Delta^{\prime} \Delta$ ), $S$ contains the eigenvectors of $\Delta \Delta^{\prime}$ such that $S^{\prime} S=I_{J}$, and $U$ contains the eigenvectors of $\Delta^{\prime} \Delta$ such that $U^{\prime} U=I_{J}$. Now, we can define $V=\tilde{S} \tilde{W}^{1 / 2}$ and $C=\tilde{U} \tilde{W}^{1 / 2}$, where the submatrices $\tilde{S}(J \times 2), \tilde{U}$ $(J \times 2)$ and $\tilde{W}(2 \times 2)$ correspond to the two largest singular values in $W$.
} 
price reduction on the other brands. Furthermore, the vector length corresponding to the $k$-th row of $V$ indicates the overall extent to which the market share of brand $k$ is influenced by competitive price reductions, that is, the vulnerability $(V)$ of brand $k$. Similarly, the vector length corresponding to the $j$-th row of $C$ indicates the overall ability of brand $j$ to affect the market shares of competitive brands by lowering the own price, that is, the clout $(C)$ of brand $j$.

\section{Insert Figure 3 about here.}

Figure 3 contains the price elasticity maps for the considered store-level data. The top-left map indicates that, in the Sioux Falls catsup market, Heinz and Rest are the most direct price competitors in the sense that they affect each other more than they affect the other competing brands. On the other hand, price competition between Del Monte and Rest is relatively weak. The asymmetric price competition effect, which is present in this market, is illustrated by the large vulnerability of the Rest brand relative to its clout. The bottom-left map for the Sioux Falls peanut butter market displays price competition between Skippy and Jif, and price competition between Peter Pan and Rest. However, the asymmetric price competition effect, which is weaker than in the previous case, is now less evident. The top-right map in the figure does not give an obvious price competition pattern for the Springfield catsup market. However, the limited clout and vulnerability of the Rest brand might be considered as an indication that "the map is not very convinced about the position of the Rest brand". This might be caused by a strong violation of the asymmetric price competition effect. Finally, also the bottom-right map for the Springfield peanut butter market does not show a clear price competition pattern. However, the small clout of the Rest brand and the even much smaller vulnerability can be seen as an indication that, in this case, the asymmetric price competition effect of Blattberg and Wisniewski (1989) is mainly, but not entirely, reversed.

Insert Table 6 about here. 


\subsection{Share-switching analysis}

Our model can be used to analyze share-switching patterns. Also this yields insights which cannot be obtained from market share attraction models. Table 6 shows the share-switching estimates, averaged over the in-sample period, for the considered markets. It reports the row-conditional share-switching fractions $\tilde{\lambda}_{l, k, t}$ and the absolute share-switching portions $\bar{\lambda}_{l, k, t}=M_{l, t-1} \tilde{\lambda}_{l, k, t}$.

A casual inspection of the share-switching fractions $\tilde{\lambda}_{l, k, t}$ in Table 6 indicates that Heinz has the most loyal customer base in the two catsup markets, whereas Peter Pan can be regarded as having the most loyal customer base in the two peanut butter markets. Furthermore, it can be seen that, compared to the Sioux Falls market, customers in the Springfield market are more loyal to the Rest brand, representing several smaller brands and private labels, than they are loyal to the more expensive national brands. This holds for both catsup and peanut butter. Finally, the shareswitching portions $\bar{\lambda}_{l, k, t}$ show some strong asymmetries. For example, in the Sioux Falls peanut butter market, on average $5.9 \%$ of the total market switches from Jif to Skippy, whereas on average only $3.7 \%$ switches from Skippy to Jif. However, for all brands the average total share coming in (the sum of column elements) and the average total share going out (the sum of corresponding row elements) are approximately equal. This is a necessary condition for stationarity of market shares. So, although we find asymmetries in share-switching, our model seems to support the finding of Lal and Padmanabhan (1995) that market shares are mostly stationary.

\subsubsection{Share-switching maps}

It is instructive to visualize the share-switching estimates in Table 6, so that switching patterns can be recognized more easily. In order to do so, we apply the multidimensional unfolding technique of Constantine and Gower (1978). This method is suitable to display asymmetric share-switching in a two-dimensional map. Alternatively, one might consider the multidimensional scaling methodology of DeSarbo and Manrai (1992). Their method is based on the distance-density model of Krumhansl 
(1978). Basically, it posits that asymmetries in brand-switching are caused by the locations of the involved brands on the map, that is, it matters whether a brand is located in a dense region with many competing brands nearby (little differentiation) or in a relatively sparse region (much differentiation). In this paper we apply the technique of Constantine and Gower (1978), and not the methodology of DeSarbo and Manrai (1992), for two reasons. First, we do not want to restrict ourselves to the condition that asymmetries in share-switching are only determined by brand differentiation relative to all competing brands. Second, the method of Constantine and Gower (1978) is more compatible with the price elasticity maps from the previous subsection.

Similar to the price elasticity maps, we identify a share-switching vulnerability point and a share-switching clout point for each brand. The vulnerability of brand $l$ is given by the $l$-th row of the $J \times 2$ matrix $V$, that is, $V_{l, .}$ Similarly, the clout of brand $k$ is given by the $k$-th row of the $J \times 2$ matrix $C$, that is, $C_{k, \cdot}$ The matrices $V$ and $C$ are constructed such that, for all brands $l$ and $k$ with $l \neq k$, the distance between $V_{l}$, and $C_{k}$, in the two-dimensional map represents the amount of share-switching from brand $l$ to brand $k$ as good as possible. Here a larger distance between the vulnerability point of brand $l$ and the clout point of brand $k$ indicates stronger share-switching from $l$ to $k$. We obtain $V$ and $C$ by minimizing the sum of squared errors $\sum_{l=1}^{J} \sum_{k \neq l}\left(\left\|V_{l, \cdot}-C_{k, .}\right\|-\overline{\bar{\lambda}}_{l, k, t}\right)^{2}$, where $\overline{\bar{\lambda}}_{l, k, t}=\bar{\lambda}_{l, k, t} / \bar{\lambda}_{l, l, t}$ are normalized share-switching portions, and $\|\cdot\|$ denotes the Euclidean norm. We consider the normalized share-switching portions $\overline{\bar{\lambda}}_{l, k, t}$, instead of $\tilde{\lambda}_{l, k, t}$ or $\bar{\lambda}_{l, k, t}$, for the following reasons. First, the absolute share-switching portions $\bar{\lambda}_{l, k, t}$ are preferred over the row-conditional share-switching fractions $\tilde{\lambda}_{l, k, t}$, as the former account for variation in the size of the market share of brand $l$ over time. This means that shareswitching, which might be substantial relative to the supplying brand $l$ but which at that moment is negligible compared to the whole market, is assigned less importance than share-switching, which is also substantial at the market level. Second, the normalization from $\bar{\lambda}_{l, k, t}$ to $\overline{\bar{\lambda}}_{l, k, t}=\bar{\lambda}_{l, k, t} / \bar{\lambda}_{l, l, t}$ implies that share-switching away 
from brand $l$ is related to the retained share of brand $l$. This makes the shareswitching measure invariant with respect to the sizes of the various brands. We note that the normalization of all share-switching portions $\bar{\lambda}_{l, k, t}$ implies that the normalized retained portions $\overline{\bar{\lambda}}_{l, l, t}$, which are not considered in the construction of $V$ and $C$, all have value one.

\section{Insert Figure 4 about here.}

Figure 4 contains the share-switching maps for the considered store-level data. The top-left map shows that, in the Sioux Falls catsup market, the leading brand Heinz poses a threat to all other brands. In the opposite direction, Heinz mainly loses share to Hunts. We further see that substantial share-switching occurs between Hunts and Del Monte. However, Del Monte suffers more from Hunts than vice versa. The top-right map displays share-switching in the Springfield catsup market. Similar to the Sioux Falls market, Heinz gains substantial share from all three competing brands, while there is little share-switching between Del Monte and Rest. Actually, the central location of the clout of Del Monte, with the vulnerability points of the three competing brands nearby, indicates that Del Monte does not gain much share from any competitor. There is relatively much share-switching between Hunts and Rest.

Finally, the bottom two maps show a strong asymmetry in share-switching between Skippy and Peter Pan in the Sioux Falls and Springfield peanut butter markets. Skippy suffers much more from Peter Pan than vice versa. In both markets, Peter Pan loses relatively much share to the Rest brand. Share-switching between Peter Pan and Rest is asymmetric in favor of the Rest brand.

\section{Conclusions}

In this paper we proposed a model for market shares which can be used to infer share-switching across brands from store-level scanner data. These insights cannot be obtained from market share attraction models, although these models could be 
taken as competitors when it comes to out-of-sample forecasting of shares. A second contribution of our model is that it allows for a decomposition of own and cross price elasticities into components attributable to changes in share-switching from each of the brands towards the brand whose market share is affected. This decomposition can, for example, be used to investigate which part of the reaction of the own market share to an own price reduction is caused by increased customer retention, and which part is not.

We illustrated our model for store-level scanner data concerning the catsup and peanut butter categories in the Sioux Falls SD and Springfield MO markets. For these data sets, our model performed well compared to the familiar market share attraction model, both in terms of in-sample fit and out-of-sample forecasting. The elasticity decompositions from our model showed that the majority of the increased market share after an own price reduction is caused by gaining additional share from competing brands, and not so much by increasing own customer retention. Furthermore, the elasticity decompositions indicated that in most cases the majority of the loss in own market share after a competitive price reduction is caused by share-switching in which the own brand is not directly involved, and not so much by decreased own customer retention.

Next, we investigated whether the resulting price elasticities were consistent with the finding of Blattberg and Wisniewski (1989) that higher-price higher-quality brands can gain more share from lower-price lower-quality brands by offering a price reduction than vice versa. This result was supported for both catsup and peanut butter in the Sioux Falls market, but it was not supported in the Springfield market. An explanation for the disparity, which seems consistent with the considered data, is that in the Springfield market the perceived quality gap between the expensive national brands and the cheaper Rest brand is not always sufficient to account for the price difference. This explanation would be in accordance with a result in Bronnenberg and Wathieu (1996).

Finally, we inferred share-switching across brands from our model. The share- 
switching estimates indicated that Heinz has the most loyal customer base in the two catsup markets, whereas Peter Pan can be regarded as having the most loyal customer base in the two peanut butter markets. Although the estimated shareswitching portions showed some strong asymmetries, the resulting market shares seemed balanced in the sense that for each brand the total share coming in and the total share going out were approximately equal. By considering two-dimensional share-switching maps, we discovered some interesting patterns in share-switching. We found that in both the Sioux Falls and Springfield catsup markets Heinz gains substantial share from all competing brands, while there is little share competition between Del Monte and the Rest brand. Furthermore, we found some strong asymmetries in both markets for peanut butter. Skippy loses much more share to Peter Pan than vice versa, and Peter Pan loses relatively much share to the Rest brand.

A limitation of our analysis is that it does not account for primary demand effects, that is, we considered how category sales are distributed across brands, but we did not consider whether the total market expands or shrinks over time. For example, it might well be that absolute sales of a brand decrease while the market share increases. In this case, the secondary demand effect (larger market share) is dominated by the primary demand effect (smaller total market). Van Heerde, Gupta and Wittink (2002) put forward a unit sales decomposition for primary and secondary demand effects that accounts for increased category volume after a price promotion. This decomposition is complementary to the frequently considered primarysecondary demand elasticity decomposition, which assumes that total category sales are held constant. By accounting for category expansion effects, Van Heerde, Gupta and Wittink (2002) find that the primary demand effect is larger than was previously believed. An interesting extension of our model would therefore be to include nonpurchase behavior in order to account for changes in primary demand. In principle, this can be done by representing all non-purchases by an "outside good", which is just regarded as another brand. Its market share is then modelled together with the market shares of the considered brands. However, a practical complication of 
this extension is that it requires information on the size of the total market. When one would have information on unit sales for each brand, the total number of store visits and the average purchase quantity, it should be possible to obtain the size of the outside good, see for example Chintagunta (2000). 


\section{Appendix A}

The model in Leeflang (1974) amounts to the following. Suppose there are $N$ households in a market for a product category for which $J$ brands are available. Households have homogeneous preferences and each household purchases precisely one unit per period. To be more specific, at time $t$, each household chooses brand $k$, $k=1, \ldots, J$, with probability $p_{k, t}$, which might depend on the marketing activity of the brand. Under these assumptions, total unit sales per brand, denoted by $N_{k, t}$, $k=1, \ldots, J$, are multinomially $\operatorname{MN}\left(N, p_{1, t}, \ldots, p_{J, t}\right)$ distributed. That is,

$$
\operatorname{Pr}\left(N_{1, t}=n_{1, t}, \ldots, N_{J, t}=n_{J, t}\right)=\frac{N !}{n_{1, t} ! \ldots n_{J, t} !} p_{1, t}^{n_{1, t}} \ldots p_{J, t}^{n_{J, t}}
$$

It follows from the properties of the multinomial distribution that

$$
\begin{aligned}
E\left(N_{1, t}, \ldots, N_{J, t}\right) & =\left(N p_{1, t}, \ldots, N p_{J, t}\right), \\
\operatorname{Cov}\left(N_{1, t}, \ldots, N_{J, t}\right) & =N \Omega_{t},
\end{aligned}
$$

where the $(i, j)$-th element of $\Omega_{t}$ is defined by

$$
\omega_{(i, j), t}=\left\{\begin{array}{ll}
p_{i, t}\left(1-p_{i, t}\right) & \text { if } i=j \\
-p_{i, t} p_{j, t} & \text { if } i \neq j
\end{array} .\right.
$$

By definition, the market share of brand $k$ at time $t$ is given by $M_{k, t}=N_{k, t} / N$, $k=1, \ldots, J$, so that it immediately follows from (A.2) and (A.3) that

$$
\begin{aligned}
E\left(M_{1, t}, \ldots, M_{J, t}\right) & =\left(p_{1, t}, \ldots, p_{J, t}\right), \\
\operatorname{Cov}\left(M_{1, t}, \ldots, M_{J, t}\right) & =\frac{1}{N} \Omega_{t} .
\end{aligned}
$$

The brand choice probabilities $p_{k, t}, k=1, \ldots, J$, are unconditional on the past. They can be related to the previous period as follows, that is,

$$
p_{k, t}=\sum_{l=1}^{J} \tilde{\lambda}_{l, k, t} p_{l, t-1},
$$

where $\tilde{\lambda}_{l, k, t}$ denotes the probability that brand $k$ is chosen given that brand $l$ was chosen during the previous period. So, $\tilde{\lambda}_{l, k, t}$ is the conditional probability of moving from brand $l$ to brand $k$. By replacing the unobserved brand choice probability $p_{k, t}$ 
in (A.7) by the observed market share $M_{k, t}$, the relationship still holds, but now only approximately. Recall that $E\left(M_{k, t}\right)=p_{k, t}$. One obtains that

$$
M_{k, t}=\sum_{l=1}^{J} \tilde{\lambda}_{l, k, t} M_{l, t-1}+e_{k, t}
$$

where $e_{k, t}$ is a disturbance term. Now, it follows from (A.6) and (A.8) that

$$
\operatorname{Cov}\left(e_{1, t}, \ldots, e_{J, t}\right)=\frac{1}{N} V_{t}
$$

where the $(i, j)$-th element of $V_{t}$ is defined by

$$
v_{(i, j), t}=\left\{\begin{array}{ll}
p_{i, t}-\sum_{l=1}^{J} \tilde{\lambda}_{l, i, t}^{2} p_{l, t-1} & \text { if } i=j \\
-\sum_{l=1}^{J} \tilde{\lambda}_{l, i, t} \tilde{\lambda}_{l, j, t} p_{l, t-1} & \text { if } i \neq j
\end{array} .\right.
$$

It can further be shown that the disturbances are uncorrelated over time.

The model is completed by specifying the transition probabilities $\tilde{\lambda}_{l, k, t}$. They are defined in a linear fashion under the conditions that $\tilde{\lambda}_{l, k, t}>0$ and $\sum_{k=1}^{J} \tilde{\lambda}_{l, k, t}=1$. At least, the $\tilde{\lambda}_{l, k, t}$ depend on the marketing instruments of brand $l$ and brand $k$ at time $t$ and time $t-1$.

One of the $J$ market share equations is redundant. In the model, the last equation is simply disregarded in the estimation procedure. Leeflang (1974, p. 134) calls this "a workable but not very elegant solution". The estimation method is essentially Feasible Generalized Least Squares [FGLS], where the probabilities $p_{k, t}$ in the covariance matrix $V_{t}$ have been replaced by the corresponding market shares $M_{k, t}$. However, as the parameters have to satisfy inequality restrictions, the estimation procedure involves optimization under inequality restrictions. Furthermore, the covariance matrix is not necessarily positive definite, as this depends on the estimated $\tilde{\lambda}_{l, k, t}$.

How does the model in Leeflang (1974) differ from the one we propose in this paper? First, the estimation results are not invariant with respect to which equation is disregarded. This is contrary to our model. Second, estimation of the parameters in the Leeflang model is more complicated, as it amounts to optimization under inequality restrictions, instead of simply maximizing the likelihood. Furthermore, 
positive definiteness of the involved covariance matrix depends on the values of $\tilde{\lambda}_{l, k, t}$. We note that our model accounts for the inequality restrictions through the functional form, and that in our model the covariance matrix is positive definite by construction. Third, both the Leeflang model and our model imply a negative correlation between market shares. This makes sense. However, in the Leeflang model this negative correlation originates from the second moment of the multinomial distribution, whereas in our model it originates from accounting for the "redistribution condition" that $\sum_{k=1}^{J} \tilde{\lambda}_{l, k, t}=1$. Finally, we note that in our model $\tilde{\lambda}_{l, k, t}$ is only influenced by the marketing instruments of the receiving brand $k$, and not by the marketing instruments of the supplying brand $l$. This is in accordance with the brand-switching models of Givon (1984) and Seetharaman and Chintagunta (1998). 


\section{Appendix B}

In this Appendix we derive the distribution of the market shares $M_{t}=\tilde{\Lambda}_{t}^{\prime} M_{t-1}+$ $E_{t}^{\prime} M_{t-1}$ after imposing the restrictions $\sum_{k=1}^{J} e_{l, k, t}=0, l=1, \ldots, J$ on the error matrix $E_{t}$. Before imposing these restrictions, the share-switching errors $e_{l, k, t}$ are independently $N\left(0, \sigma_{k, t}^{2}\right)$ distributed with $\sigma_{k, t}^{2}=\sigma^{2} M_{k, t-1}^{\gamma}$.

We first derive the distribution of $\left(e_{l, 1, t}, \ldots, e_{l, J, t}\right)^{\prime}$, given $\sum_{k=1}^{J} e_{l, k, t}=0, l=$ $1, \ldots, J$. Without imposing the summation restriction, the density of $\left(e_{l, 1, t}, \ldots, e_{l, J, t}\right)^{\prime}$ is given by

$$
f\left(e_{l, 1, t}, \ldots, e_{l, J, t}\right) \propto \exp \left(-\frac{1}{2} \sum_{k=1}^{J} \frac{e_{l, k, t}^{2}}{\sigma_{k, t}^{2}}\right)
$$

where $\propto$ denotes "is proportional to". In order to impose that $\sum_{k=1}^{J} e_{l, k, t}=0$, we make a transformation of variables from $\left(e_{l, 1, t}, \ldots, e_{l, J-1, t}, e_{l, J, t}\right)^{\prime}$ to $\left(e_{l, 1, t}, \ldots, e_{l, J-1, t}, z\right)^{\prime}$ with $z=\sum_{k=1}^{J} e_{l, k, t}$. Note that $e_{l, J, t}=z-\sum_{k=1}^{J-1} e_{l, k, t}$. As the Jacobian matrix of this transformation has determinant one, the transformed density becomes

$$
f\left(e_{l, 1, t}, \ldots, e_{l, J-1, t}, z\right) \propto \exp \left(-\frac{1}{2}\left[\sum_{k=1}^{J-1} \frac{e_{l, k, t}^{2}}{\sigma_{k, t}^{2}}+\frac{\left(z-\sum_{k=1}^{J-1} e_{l, k, t}\right)^{2}}{\sigma_{J, t}^{2}}\right]\right) .
$$

Now, imposing the restriction $z=\sum_{k=1}^{J} e_{l, k, t}=0$ gives

$$
\begin{aligned}
f\left(e_{l, 1, t}, \ldots, e_{l, J-1, t}, 0\right) & \propto \exp \left(-\frac{1}{2}\left[\sum_{k=1}^{J-1} \frac{e_{l, k, t}^{2}}{\sigma_{k, t}^{2}}+\frac{\left(\sum_{k=1}^{J-1} e_{l, k, t}\right)^{2}}{\sigma_{J, t}^{2}}\right]\right) \\
& =\exp \left(-\frac{1}{2} \tilde{e}_{l, t}^{\prime} \Gamma_{t} \tilde{e}_{l, t}\right)
\end{aligned}
$$

with $\tilde{e}_{l, t}=\left(e_{l, 1, t}, \ldots, e_{l, J-1, t}\right)^{\prime}$ and $\Gamma_{t}=\frac{1}{\sigma_{J, t}^{2}} \iota_{J-1} \iota_{J-1}^{\prime}+\operatorname{diag}\left(\frac{1}{\sigma_{1, t}^{2}}, \ldots, \frac{1}{\sigma_{J-1, t}^{2}}\right)$, where the diag operator transforms a vector into a diagonal matrix with the vector elements on the diagonal. It follows from (B.3) that $\left(e_{l, 1, t}, \ldots, e_{l, J-1, t}\right)^{\prime} \sim N\left(0, \Omega_{t}\right)$ with

$$
\begin{aligned}
\Omega_{t} & =\Gamma_{t}^{-1} \\
& =-\frac{1}{\sum_{j=1}^{J} \sigma_{j, t}^{2}}\left(\begin{array}{c}
\sigma_{1, t}^{2} \\
\vdots \\
\sigma_{J-1, t}^{2}
\end{array}\right)\left(\sigma_{1, t}^{2} \cdots \sigma_{J-1, t}^{2}\right)+\operatorname{diag}\left(\sigma_{1, t}^{2}, \ldots, \sigma_{J-1, t}^{2}\right),
\end{aligned}
$$

$l=1, \ldots, J$. We note that it is easily verified that $\Omega_{t} \Gamma_{t}=I_{J-1}$, the $(J-1) \times(J-1)$ identity matrix, so that $\Omega_{t}$ is indeed the inverse of $\Gamma_{t}$. By substituting $\sigma_{k, t}^{2}=$ 
$\sigma^{2} M_{k, t-1}^{\gamma}$ into (B.4), it is obtained that

$$
\begin{aligned}
& \Omega_{t}=\sigma^{2} \\
& {\left[\begin{array}{c}
1 \\
\sum_{j=1}^{J} M_{j, t-1}^{\gamma}
\end{array}\left(\begin{array}{c}
M_{1, t-1}^{\gamma} \\
\vdots \\
M_{J-1, t-1}^{\gamma}
\end{array}\right)\left(M_{1, t-1}^{\gamma} \cdots M_{J-1, t-1}^{\gamma}\right)+\operatorname{diag}\left(M_{1, t-1}^{\gamma}, \ldots, M_{J-1, t-1}^{\gamma}\right)\right] .}
\end{aligned}
$$

Finally, as $M_{t}=\tilde{\Lambda}_{t}^{\prime} M_{t-1}+E_{t}^{\prime} M_{t-1}$, so that

$$
\left(\begin{array}{c}
M_{1, t} \\
\vdots \\
M_{J-1, t}
\end{array}\right)=\sum_{l=1}^{J} M_{l, t-1}\left(\begin{array}{c}
\tilde{\lambda}_{l, 1, t} \\
\vdots \\
\tilde{\lambda}_{l, J-1, t}
\end{array}\right)+\sum_{l=1}^{J} M_{l, t-1}\left(\begin{array}{c}
e_{l, 1, t} \\
\vdots \\
e_{l, J-1, t}
\end{array}\right),
$$

and $\left(e_{l, 1, t}, \cdots, e_{l, J-1, t}\right)^{\prime}, l=1 \ldots, J$, are independently distributed, it follows that

$$
\tilde{M}_{t}=\left(\begin{array}{c}
M_{1, t} \\
\vdots \\
M_{J-1, t}
\end{array}\right) \sim N\left(\mu_{t}, \sigma^{2} V_{t}\right)
$$

where

$$
\mu_{t}=\left(\begin{array}{c}
\sum_{l=1}^{J} \tilde{\lambda}_{l, 1, t} M_{l, t-1} \\
\vdots \\
\sum_{l=1}^{J} \tilde{\lambda}_{l, J-1, t} M_{l, t-1}
\end{array}\right)
$$

and

$$
\begin{aligned}
V_{t}= & \sum_{l=1}^{J} M_{l, t-1}^{2} \\
& {\left[\begin{array}{c}
1 \\
\left.-\frac{1}{\sum_{j=1}^{J} M_{j, t-1}^{\gamma}}\left(\begin{array}{c}
M_{1, t-1}^{\gamma} \\
\vdots \\
M_{J-1, t-1}^{\gamma}
\end{array}\right)\left(M_{1, t-1}^{\gamma} \cdots M_{J-1, t-1}^{\gamma}\right)+\operatorname{diag}\left(M_{1, t-1}^{\gamma}, \ldots, M_{J-1, t-1}^{\gamma}\right)\right] .
\end{array}\right.}
\end{aligned}
$$

We note that by analogy with $\Omega_{t}=\Gamma_{t}^{-1}$, the inverse of $V_{t}$ is given by $V_{t}^{-1}=$ $\frac{1}{\sum_{l=1}^{J} M_{l, t-1}^{2}}\left[M_{J, t-1}^{-\gamma} \iota_{J-1} \iota_{J-1}^{\prime}+\operatorname{diag}\left(M_{1, t-1}^{-\gamma}, \ldots, M_{J-1, t-1}^{-\gamma}\right)\right]$. 


\section{References}

Allenby G.M. and P.E. Rossi (1991), "Quality Perceptions and Asymmetric Switching Between Brands", Marketing Science, 10 (3), 185-204.

Bell D.E., R.L. Keeney and J.D.C. Little (1975), "A Market Share Theorem", Journal of Marketing Research, 12 (May), 136-141.

Blattberg R.C. and K.J. Wisniewski (1989), "Price-Induced Patterns of Competition", Marketing Science, 8 (4), 291-309.

Brodie R. and C.A. De Kluyver (1984), "Attraction Versus Linear and Multiplicative Market Share Models: An Empirical Evaluation", Journal of Marketing Research, 11 (May), 194-201.

Bronnenberg B.J. and L. Wathieu (1996), "Asymmetric Promotion Effects and Brand Positioning", Marketing Science, 15 (4), 379-394.

Bucklin R.E. and J.M. Lattin (1991), "A Two-State Model of Purchase Incidence and Brand Choice", Marketing Science, 10 (1), 24-39.

Bucklin R.E., G.J. Russell and V. Srinivasan (1998), "A Relationship Between Market Share Elasticities and Brand Switching Probabilities", Journal of Marketing Research, 35 (February), 99-113.

Chen Y., V. Kanetkar and D.L. Weiss (1994), "Forecasting Market Shares with Disaggregate or Pooled Data: A Comparison of Attraction Models", International Journal of Forecasting, 10, 263-276.

Chintagunta P.K. (2000), "A Flexible Aggregate Logit Demand Model”, working paper, University of Chicago.

Constantine A.G. and J.C. Gower (1978), "Graphical Representations of Asymmetric Matrices", Applied Statistics, 27 (3) 297-304. 
Cooper L.G. (1993), "Market-Share Models" in J. Eliashberg and G.L. Lilien (eds.), Handbooks in Operations Research and Management Science, Vol. 5, Elsevier Science Publishers.

Cooper L.G. (1988), "Competitive Maps: The Structure Underlying Asymmetric Cross Elasticities", Management Science, 34 (June), 707-723.

Cooper L.G. and M. Nakanishi (1988), Market Share Analysis: Evaluating Competitive Marketing Effectiveness, Kluwer Academic Publishers.

DeSarbo W.S. and A.K. Manrai (1992), "A New Multidimensional Scaling Methodology for the Analysis of Asymmetric Proximity Data in Marketing Research", Marketing Science, 11 (1), 1-20.

Doornik J.A. (1998), Object-Oriented Matrix Programming using Ox 2.0, Timberlake Consultants, London, http://www.nuff.ox.ac.uk/Users/Doornik.

Fok D., P.H. Franses and R. Paap (2002), "Econometric Analysis of the Market Share Attraction Model" in P.H. Franses and A.L. Montgomery (eds.), Advances in Econometrics Vol. 16: Econometric Models in Marketing, Elsevier Science Publishers.

Givon M. (1984), "Variety Seeking Through Brand Switching", Marketing Science, $3(1), 1-22$.

Golub G.H. and C.F. van Loan (1989), Matrix Computations, The John Hopkins University Press.

Guadagni P.M. and J.D.C. Little (1983), “A Logit Model of Brand Choice Calibrated on Scanner Data", Marketing Science, 2 (3), 203-238.

Gupta S., P. Chintagunta, A. Kaul and D.R. Wittink (1996), "Do Household Scanner Data Provide Representative Inferences From Brand Choices: A Comparison With Store Data", Journal of Marketing Research, 33 (November), 383-398.

Hardie B.G.S., E.J. Johnson and P.S. Fader (1993), "Modeling Loss Aversion and 
Reference Dependence Effects on Brand Choice", Marketing Science, 12 (4), 378-394.

Kamakura W.A. and G.J. Russell (1989), "A Probabilistic Choice Model for Market Segmentation and Elasticity Structure", Journal of Marketing Research, 26 (November), 379-390.

Krumhansl C.L. (1978), "Concerning the Applicability of Geometric Models to Similarity Data: The Interrelationship Between Similarity and Spatial Density", Psychological Review, 85, 445-463.

Kumar V. and T.B. Heath (1990), "A Comparative Study of Market Share Models Using Disaggregate Data", International Journal of Forecasting, 6, 163-174.

Lal R. and V. Padmanabhan (1995), "Competitive Response and Equilibria", Marketing Science, 14 (3), G101-G108.

Leeflang P.S.H. (1974), Mathematical Models in Marketing, Stenfert Kroese, Leiden. Leeflang P.S.H., D.R. Wittink, M. Wedel and P.A. Naert (2000), Building Models for Marketing Decisions, Kluwer Academic Publishers.

Magnus J.R. and H. Neudecker (1999), Matrix Differential Calculus with Applications in Statistics and Econometrics, John Wiley.

McAlister L. and E. Pessemier (1982), "Variety Seeking Behavior: An Interdisciplinary Review", Journal of Consumer Research, 9 (December), 311-322.

McFadden D. (1974), "Conditional Logit Analysis of Qualitative Choice Behavior", in P. Zarembka (ed.), Frontiers in Econometrics, Chapter 4, Academic Press.

Naert P.A. and M. Weverbergh (1981), "On the Prediction Power of Market Share Attraction Models", Journal of Marketing Research, 18 (May), 146-153.

Russell G.J. and W.A. Kamakura (1994), "Understanding Brand Competition Using Micro and Macro Scanner Data", Journal of Marketing Research, 31 (May), 
$289-303$

Seetharaman P.B. and P. Chintagunta (1998), "A Model of Inertia and VarietySeeking with Marketing Variables", International Journal of Research in Marketing, $15,1-17$.

Sethuraman R., V. Srinivasan and D. Kim (1999), "Asymmetric and Neighborhood Cross-Price Effects: Some Empirical Generalizations", Marketing Science, 18 (1), $23-41$.

Van Heerde H.J., S. Gupta and D.R. Wittink (2002), "Is 3/4 of the Sales Promotion Bump Due to Brand Switching? No, it is 1/3", Journal of Marketing Research, forthcoming. 
Table 1: A summary of the data, that is, the average values and the standard deviations (given in parentheses) of the market shares, prices and 0/1 display variables.

\begin{tabular}{|c|c|c|c|c|c|c|}
\hline & \multicolumn{2}{|c|}{ mshare } & \multicolumn{2}{|c|}{ price } & \multicolumn{2}{|c|}{ display } \\
\hline \multicolumn{7}{|l|}{ catsup 1} \\
\hline Heinz & 0.51 & $(0.22)$ & 1.16 & $(0.10)$ & 0.41 & $(0.49)$ \\
\hline Hunts & 0.26 & (0.19) & 1.09 & $(0.09)$ & 0.54 & $(0.50)$ \\
\hline Del Monte & 0.17 & $(0.16)$ & 1.09 & $(0.09)$ & 0.40 & $(0.49)$ \\
\hline Rest & 0.07 & $(0.08)$ & 0.87 & $(0.05)$ & 0.09 & $(0.28)$ \\
\hline \multicolumn{7}{|l|}{ catsup 2} \\
\hline Heinz & 0.37 & $(0.16)$ & 1.34 & $(0.07)$ & 0.68 & $(0.47)$ \\
\hline Hunts & 0.22 & $(0.14)$ & 1.34 & $(0.11)$ & 0.75 & $(0.43)$ \\
\hline Del Monte & 0.10 & $(0.09)$ & 1.37 & $(0.09)$ & 0.56 & $(0.50)$ \\
\hline Rest & 0.30 & $(0.11)$ & 0.84 & $(0.07)$ & 0.88 & $(0.33)$ \\
\hline \multicolumn{7}{|l|}{ pbutter 1} \\
\hline Skippy & 0.31 & $(0.19)$ & 1.68 & $(0.12)$ & 0.39 & $(0.49)$ \\
\hline Jif & 0.25 & $(0.13)$ & 1.72 & $(0.11)$ & 0.17 & $(0.38)$ \\
\hline Peter Pan & 0.25 & $(0.16)$ & 1.68 & $(0.16)$ & 0.35 & $(0.48)$ \\
\hline Rest & 0.19 & $(0.11)$ & 1.36 & $(0.12)$ & 0.19 & $(0.39)$ \\
\hline \multicolumn{7}{|l|}{ pbutter 2} \\
\hline Skippy & 0.10 & $(0.06)$ & 1.78 & $(0.21)$ & 0.10 & $(0.31)$ \\
\hline Jif & 0.16 & $(0.07)$ & 1.81 & $(0.20)$ & 0.10 & $(0.30)$ \\
\hline Peter Pan & 0.36 & $(0.16)$ & 1.70 & $(0.25)$ & 0.67 & $(0.47)$ \\
\hline Rest & 0.37 & $(0.13)$ & 1.23 & $(0.13)$ & 0.66 & $(0.47)$ \\
\hline
\end{tabular}


Table 2: Estimates of the marketing-mix response parameters and the variance parameters. The estimated standard errors are given in parentheses.

\begin{tabular}{lcccc}
\hline & catsup 1 & catsup 2 & pbutter 1 & pbutter 2 \\
\hline$\beta_{1}$ (price) & $-0.860^{* * *}$ & $-1.099^{* * *}$ & $-0.686^{* * *}$ & $-0.406^{* * *}$ \\
& $(0.110)$ & $(0.145)$ & $(0.079)$ & $(0.040)$ \\
$\beta_{2}$ (display) & $0.452^{* * *}$ & $0.383^{* *}$ & -0.046 & 0.129 \\
& $(0.108)$ & $(0.166)$ & $(0.148)$ & $(0.108)$ \\
$\sigma^{2}$ & $0.291^{* * *}$ & $0.171^{* * *}$ & $0.103^{* * *}$ & $0.102^{* * *}$ \\
& $(0.058)$ & $(0.040)$ & $(0.026)$ & $(0.022)$ \\
$\gamma$ & $0.870^{* * *}$ & $1.043^{* * *}$ & $0.419^{* * *}$ & $0.987^{* * *}$ \\
& $(0.081)$ & $(0.115)$ & $(0.145)$ & $(0.111)$ \\
\hline
\end{tabular}

** significant at $5 \%$.

*** significant at $1 \%$. 
Table 3: In-sample fit and out-of-sample forecasting performance.

\begin{tabular}{|c|c|c|c|c|c|}
\hline & & catsup 1 & catsup 2 & pbutter 1 & pbutter 2 \\
\hline \multicolumn{6}{|c|}{ in-sample } \\
\hline \multirow[t]{3}{*}{ RMSE } & our model & 0.142 & 0.098 & 0.116 & 0.078 \\
\hline & full effects & 0.132 & 0.094 & 0.104 & 0.090 \\
\hline & diff. effects & 0.143 & 0.103 & 0.123 & 0.111 \\
\hline \multirow[t]{3}{*}{ MAE } & our model & 0.101 & 0.069 & 0.083 & 0.055 \\
\hline & full effects & 0.092 & 0.068 & 0.075 & 0.064 \\
\hline & diff. effects & 0.099 & 0.076 & 0.090 & 0.078 \\
\hline \multicolumn{6}{|c|}{ out-of-sample } \\
\hline \multirow[t]{3}{*}{ RMSE } & our model & 0.147 & 0.103 & 0.120 & 0.084 \\
\hline & full effects & 0.162 & 0.119 & 0.146 & 0.111 \\
\hline & diff. effects & 0.139 & 0.116 & 0.160 & 0.213 \\
\hline \multirow[t]{3}{*}{ MAE } & our model & 0.105 & 0.083 & 0.098 & 0.062 \\
\hline & full effects & 0.114 & 0.087 & 0.112 & 0.075 \\
\hline & diff. effects & 0.099 & 0.089 & 0.127 & 0.154 \\
\hline
\end{tabular}


Table 4: Estimated market-share price elasticities $\delta_{k, j, t}$ for the two catsup markets, decomposed into components $\eta_{l \rightarrow k, j, t}$ attributable to each of the supplying brands. The reported values amount to averages over time. The index $j$ indicates the brand whose price is changed, the index $k$ indicates the brand whose market share is affected, and the index $l$ indicates the supplying brand in the elasticity decomposition $(1=$ Heinz, $2=$ Hunts, $3=$ Del Monte, $4=$ Rest $)$. The market-share price elasticities are written in bold.

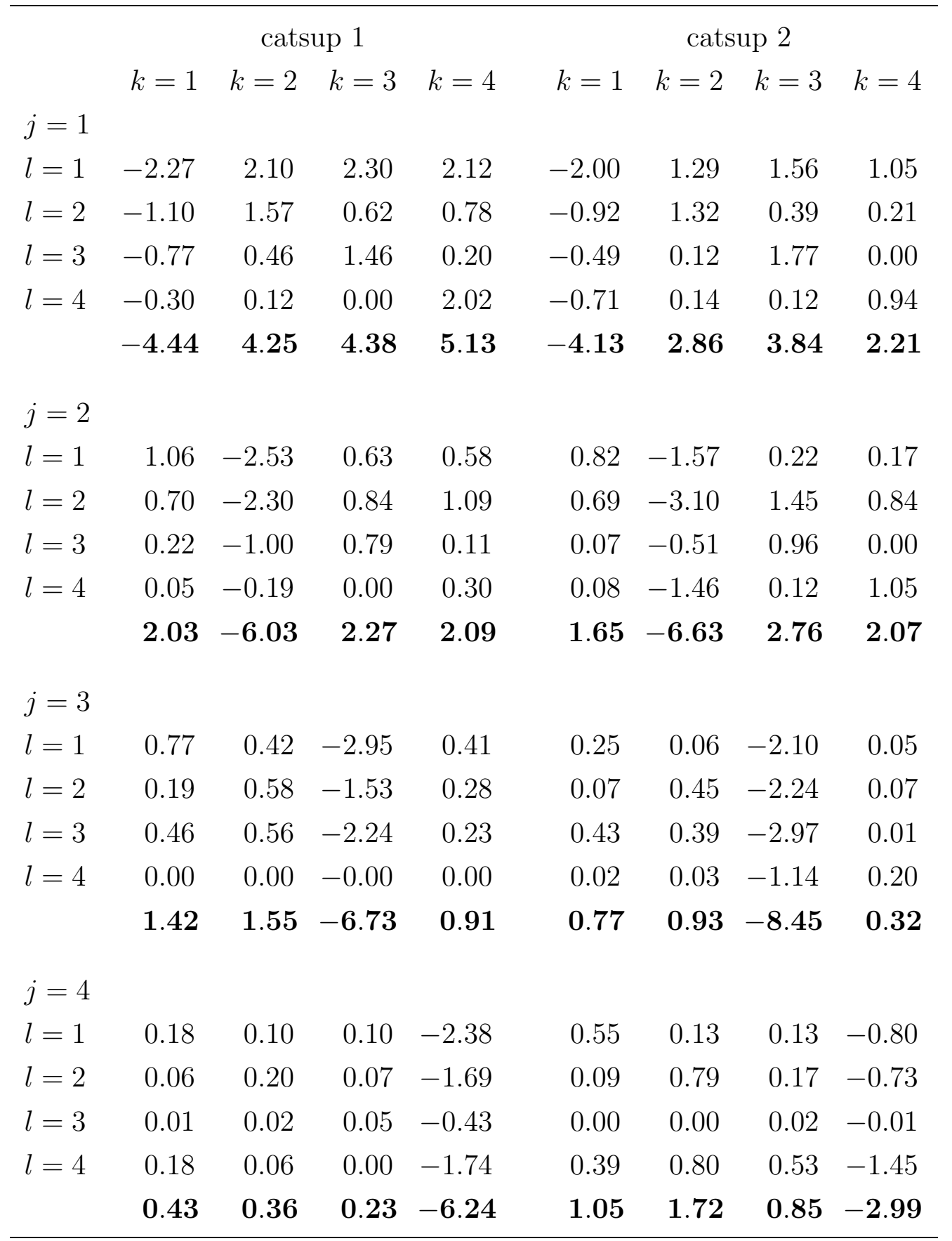


Table 5: Estimated market-share price elasticities $\delta_{k, j, t}$ for the two peanut butter markets, decomposed into components $\eta_{l \rightarrow k, j, t}$ attributable to each of the supplying brands. The reported values amount to averages over time. The index $j$ indicates the brand whose price is changed, the index $k$ indicates the brand whose market share is affected, and the index $l$ indicates the supplying brand in the elasticity decomposition ( 1 = Skippy, $2=$ Jif, 3 = Peter Pan, 4 = Rest). The market-share price elasticities are written in bold.

\begin{tabular}{|c|c|c|c|c|c|c|c|c|}
\hline \multirow{3}{*}{$j=1$} & \multicolumn{4}{|c|}{ pbutter 1} & \multicolumn{4}{|c|}{ pbutter 2} \\
\hline & $k=1$ & $k=2$ & $k=3$ & $k=4$ & $k=1$ & $k=2$ & $k=3$ & $k=4$ \\
\hline & & & & & & & & \\
\hline$l=1$ & -2.48 & 0.99 & 1.07 & 0.79 & -1.61 & 0.31 & 0.20 & 0.10 \\
\hline$l=2$ & -1.87 & 1.53 & 0.28 & 0.23 & -0.82 & 0.29 & 0.06 & 0.03 \\
\hline$l=3$ & -0.51 & 0.08 & 0.29 & 0.09 & -0.86 & 0.05 & 0.15 & 0.05 \\
\hline \multirow[t]{2}{*}{$l=4$} & -1.04 & 0.19 & 0.13 & 1.01 & -1.21 & 0.08 & 0.04 & 0.25 \\
\hline & -5.90 & 2.79 & 1.78 & 2.12 & -4.49 & 0.72 & 0.45 & 0.43 \\
\hline \multicolumn{9}{|l|}{$j=2$} \\
\hline$l=1$ & 0.90 & -1.49 & 0.26 & 0.20 & 0.52 & -0.47 & 0.04 & 0.02 \\
\hline$l=2$ & 1.48 & -2.86 & 0.71 & 0.55 & 0.51 & -1.71 & 0.42 & 0.20 \\
\hline$l=3$ & 0.10 & -1.30 & 0.99 & 0.34 & 0.09 & -1.04 & 0.37 & 0.12 \\
\hline \multirow[t]{2}{*}{$l=4$} & 0.21 & -1.00 & 0.15 & 1.02 & 0.14 & -1.23 & 0.09 & 0.49 \\
\hline & 2.69 & -6.65 & 2.11 & 2.12 & 1.25 & -4.44 & 0.93 & 0.83 \\
\hline \multicolumn{9}{|l|}{$j=3$} \\
\hline$l=1$ & 0.98 & 0.28 & -1.50 & 0.24 & 0.65 & 0.09 & -0.26 & 0.03 \\
\hline$l=2$ & 0.26 & 0.73 & -1.04 & 0.11 & 0.19 & 0.84 & -0.54 & 0.08 \\
\hline$l=3$ & 0.30 & 0.90 & -2.30 & 1.21 & 0.53 & 0.69 & -1.34 & 0.74 \\
\hline \multirow[t]{2}{*}{$l=4$} & 0.13 & 0.13 & -0.73 & 0.71 & 0.16 & 0.17 & -0.64 & 0.58 \\
\hline & 1.67 & 2.04 & -5.58 & 2.28 & 1.53 & 1.79 & -2.79 & 1.42 \\
\hline \multicolumn{9}{|l|}{$j=4$} \\
\hline$l=1$ & 0.42 & 0.13 & 0.14 & -0.99 & 0.25 & 0.03 & 0.02 & -0.11 \\
\hline$l=2$ & 0.12 & 0.35 & 0.07 & -0.70 & 0.07 & 0.31 & 0.06 & -0.22 \\
\hline$l=3$ & 0.08 & 0.21 & 0.79 & -1.32 & 0.14 & 0.17 & 0.59 & -0.67 \\
\hline \multirow[t]{2}{*}{$l=4$} & 0.56 & 0.52 & 0.37 & -2.24 & 0.62 & 0.66 & 0.38 & -1.00 \\
\hline & 1.18 & 1.20 & 1.36 & -5.25 & 1.08 & 1.18 & 1.05 & -1.99 \\
\hline
\end{tabular}


Table 6: Share-switching estimates, that is, the row-conditional share-switching fractions $\tilde{\lambda}_{l, k, t}$ from brand $l$ to brand $k$ and the absolute share-switching portions $\bar{\lambda}_{l, k, t}=M_{l, t-1} \tilde{\lambda}_{l, k, t}$ from brand $l$ to brand $k$. The reported values amount to averages over time.

$k$

share-switching fractions $k$

share-switching portions

catsup 1

$\begin{array}{lllllllll}\text { Heinz } & 0.692 & 0.157 & 0.116 & 0.035 & 0.333 & 0.086 & 0.063 & 0.018 \\ \text { Hunts } & 0.270 & 0.567 & 0.113 & 0.049 & 0.079 & 0.134 & 0.033 & 0.013 \\ \text { Del Monte } & 0.277 & 0.174 & 0.533 & 0.015 & 0.056 & 0.035 & 0.083 & 0.003 \\ \text { Rest } & 0.518 & 0.087 & 0.000 & 0.396 & 0.034 & 0.005 & 0.000 & 0.025\end{array}$

catsup 2

$\begin{array}{lllllllll}\text { Heinz } & 0.849 & 0.063 & 0.019 & 0.069 & 0.318 & 0.029 & 0.009 & 0.031\end{array}$

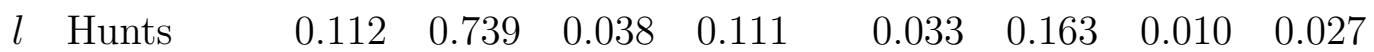

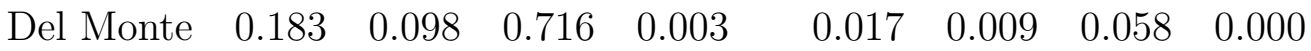

$\begin{array}{lllllllll}\text { Rest } & 0.078 & 0.086 & 0.016 & 0.821 & 0.023 & 0.027 & 0.005 & 0.243\end{array}$

pbutter 1

$\begin{array}{lllllllll}\text { Skippy } & 0.677 & 0.117 & 0.136 & 0.070 & 0.185 & 0.037 & 0.044 & 0.025\end{array}$

$l \quad$ Jif $\quad \begin{array}{llllllll}0.211 & 0.626 & 0.102 & 0.062 & 0.059 & 0.154 & 0.029 & 0.017\end{array}$

$\begin{array}{lllllllll}\text { Peter Pan } & 0.035 & 0.119 & 0.719 & 0.127 & 0.010 & 0.037 & 0.175 & 0.038\end{array}$

$\begin{array}{lllllllll}\text { Rest } & 0.135 & 0.134 & 0.095 & 0.637 & 0.029 & 0.030 & 0.019 & 0.113\end{array}$

pbutter 2

\begin{tabular}{|c|c|c|c|c|c|c|c|c|}
\hline Skippy & 0.605 & 0.131 & 0.175 & 0.090 & 0.060 & 0.013 & 0.019 & 0.009 \\
\hline Jif & 0.074 & 0.592 & 0.224 & 0.110 & 0.013 & 0.097 & 0.041 & 0.019 \\
\hline Peter Pan & 0.029 & 0.068 & 0.745 & 0.158 & 0.012 & 0.029 & 0.263 & 0.066 \\
\hline Rest & 0.047 & 0.090 & 0.113 & 0.750 & 0.018 & 0.034 & 0.044 & 0.264 \\
\hline
\end{tabular}



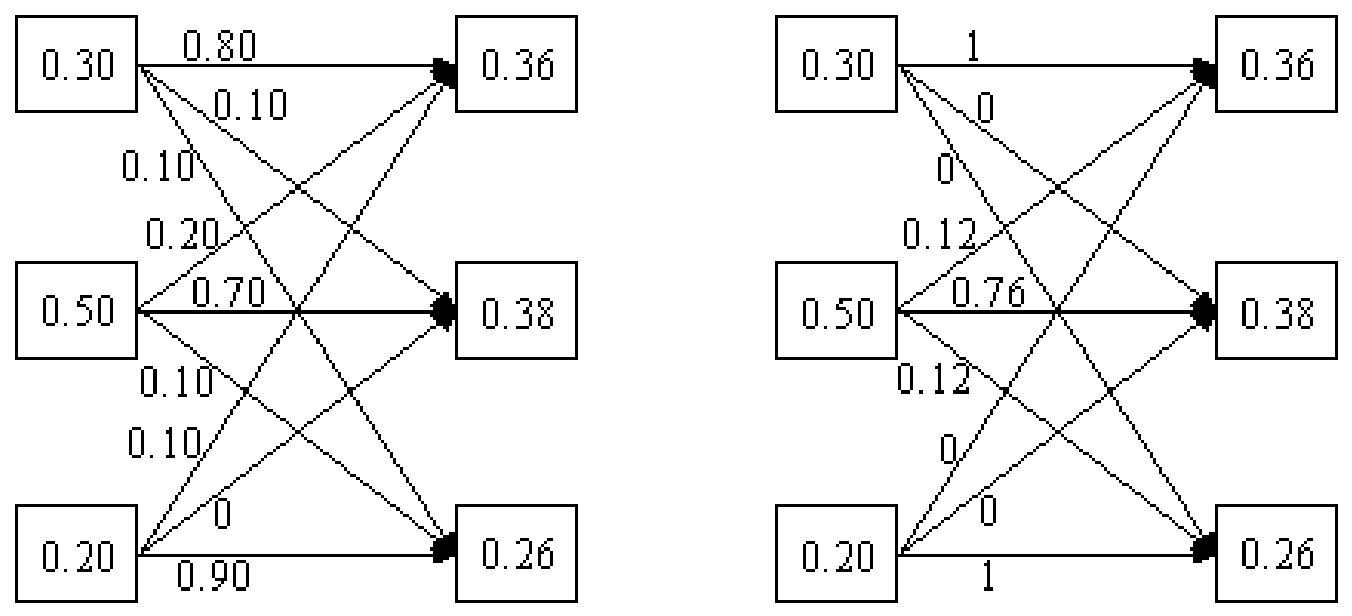

Figure 1: A numerical example of share-switching. 


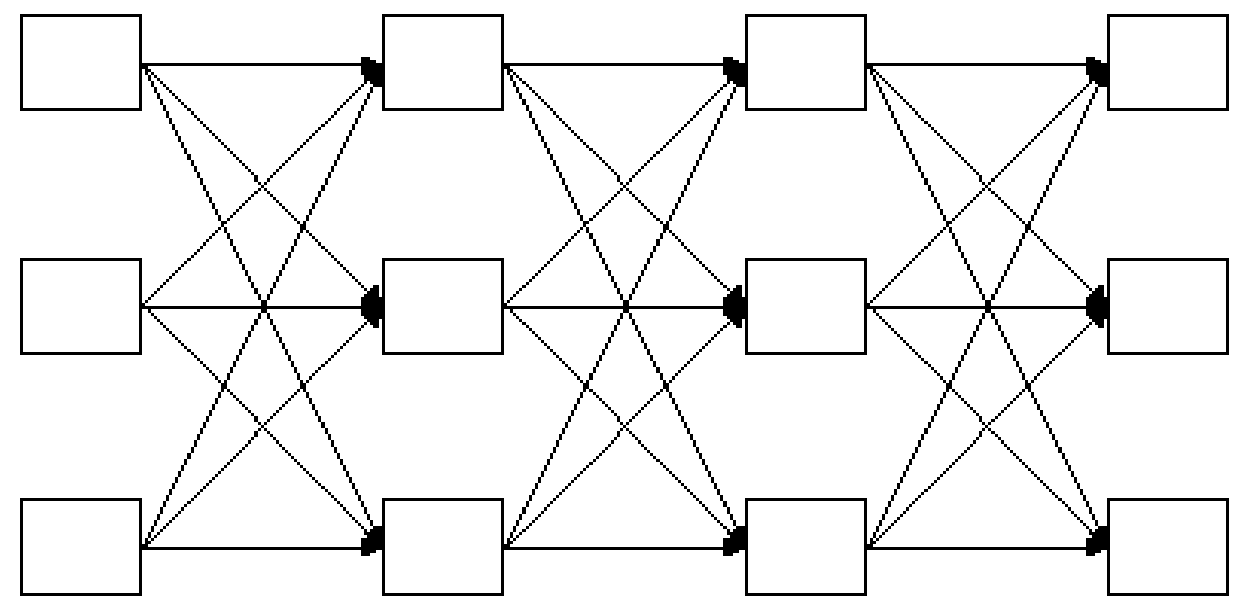

Figure 2: Illustration of share-switching for multiple periods. 

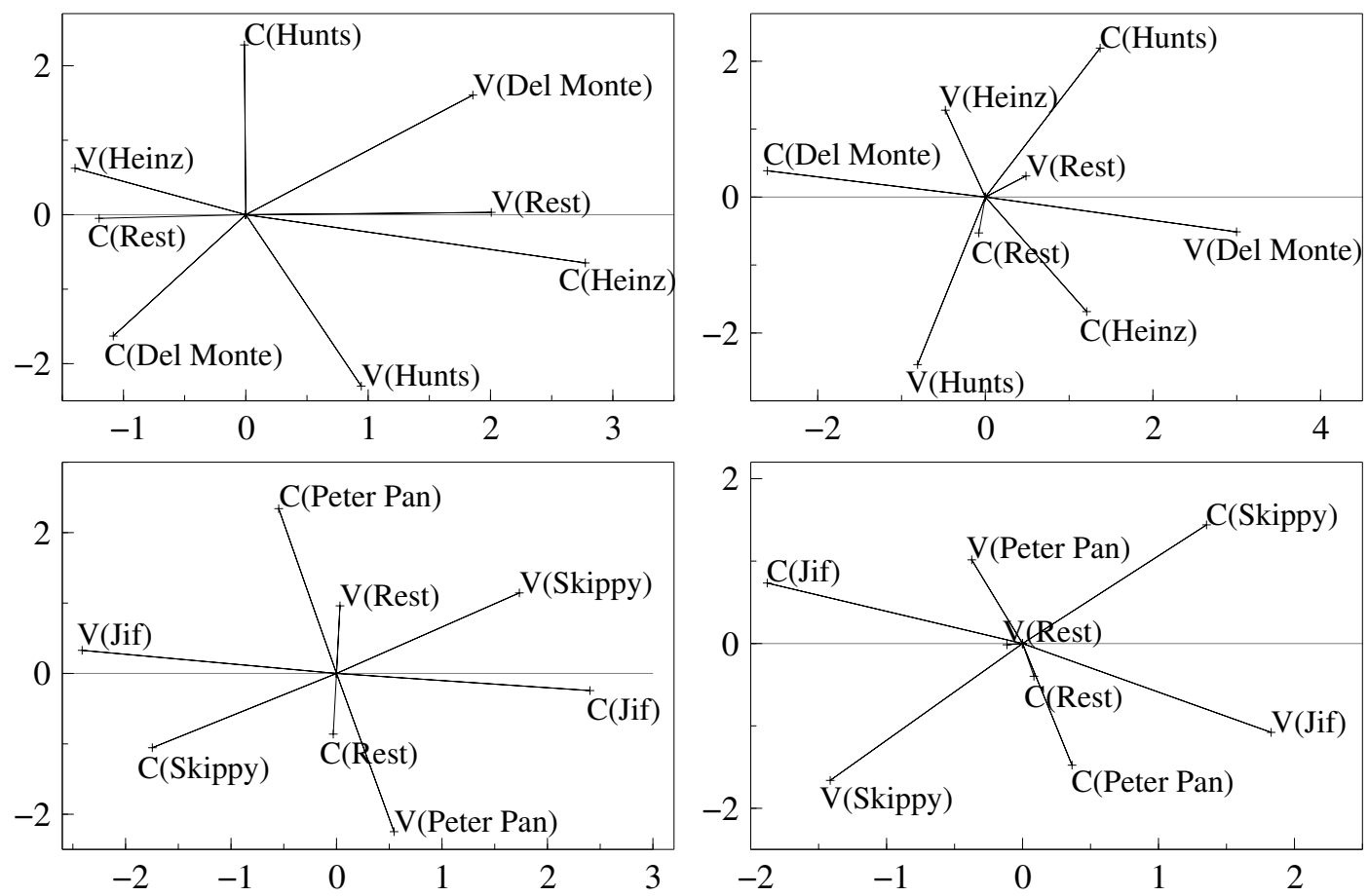

Figure 3: Price elasticity maps for the catsup and peanut butter categories in the Sioux Falls SD market and the Springfield MO market. 

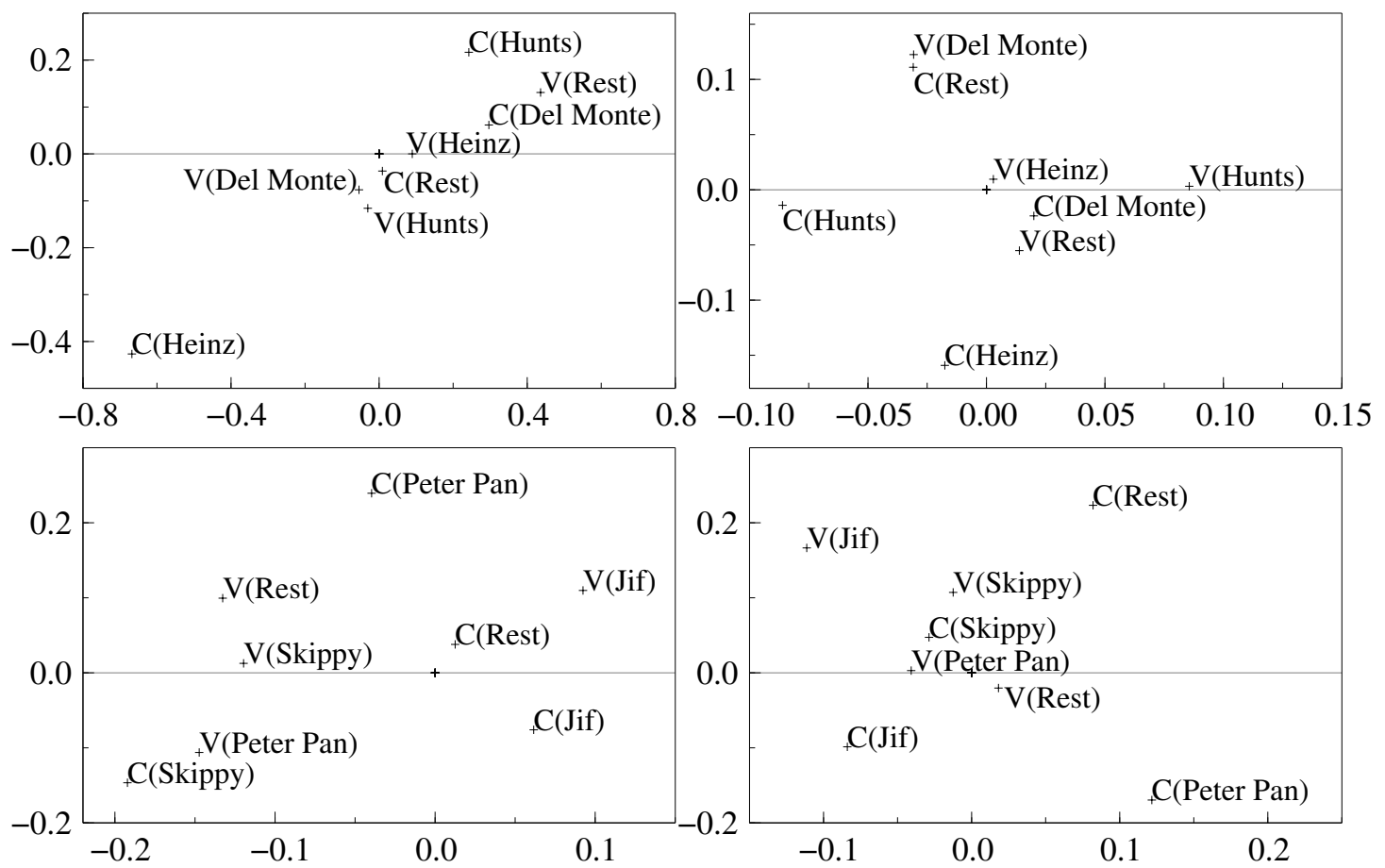

Figure 4: Share-switching maps for the catsup and peanut butter categories in the Sioux Falls SD market and the Springfield MO market. 